\title{
Shallow-water phoxocephalid Amphipoda (Crustacea) of Korea
}

\author{
Young Won Jo \\ Institute of Taxonomic Zoology, University of Amsterdam, P.O. Box 4766, 1009 AT Amsterdam, \\ The Netherlands
}

Keywords: Amphipoda, Mandibulophoxus, Grandifoxus, Korea

\begin{abstract}
Five new species of phoxocephalid amphipods from sandy beaches in Korea belonging to two genera are described and figured: Mandibulophoxus mai n. sp., M. hongae n. sp., Grandifoxus malipoensis n. sp., G. cuspis n. sp., and G. bangpoensis n. sp. Keys to the known species and diagnoses of the genera are provided. The male characters of the genus Mandibulophoxus are given for the first time, but no male specimens of Grandifoxus were obtained during the present study.
\end{abstract}

\section{Résumé}

Cinq nouvelles espèces d'Amphipodes Phoxocéphalides appartenant à deux genres, sont décrites et figurées de plages de sable de Corée: Mandibulophoxus mai n. sp., M. hongae n. sp., Grandifoxus malipoensis n. sp., G. cuspis n. sp. et $G$. bangpoensis n. sp. Sont fournies des clefs de détermination pour les espèces connues et des diagnoses des deux genres. Les caractères du mâle de Mandibulophoxus sont pour la première fois décrits, mais les mâles de Grandifoxus n'ont pas pu être trouvés lors de cette étude.

\section{Introduction}

At the end of the 1970s Gurjanova $(1977 ; 1980 \mathrm{a}, \mathrm{b})$, Barnard \& Drummond (1976; 1978) and Barnard (1979) revised the amphipod family Phoxocephalidae. In their reports Gurjanova (1977; 1980b) divided the family Phoxocephalidae sensu stricto into 4 subfamilies, whereas Barnard \& Drummond (1978) splitted the family into 9 subfamilies based on their extensive studies of Australian material.
Gurjanova (1980a) retained 32 species within the genus Pontharpinia, Barnard (1979) carved several new genera out of the polytypic Paraphoxus, and left Pontharpinia with a single species (Barnard \& Drummond, 1976).

The genus Grandifoxus was separated from Paraphoxus by Barnard (1979) and several species were designated to it (Barnard, 1980). Later Coyle (1982) redescribed 3 species, $G$. longirostris, $G$. lindbergi and $G$. nasuta (also giving some remarks on $G$. grandis) based on Alaskan material and described 3 new species, G. acanthinus, G. vulpinus and $G$. aciculata, from the Bering Sea. In the present study, 3 new species of the genus are described from Korean waters. The animals belonging to this genus are primarily distributed along the west coast (Yellow Sea side) of the country, whereas no specimens were obtained on the east coast (Japan Sea side).

Until recently 2 species of the genus Mandibulophoxus have been reported from the Indian region (M. uncirostratus) and the west American coast including Alaskan waters ( $M$. gilesi). This study further attributes two species, $M$. mai n. sp. and $M$. hongae $\mathrm{n}$. sp. to the genus. The large species, $M . m a i$, is found along the west and the south coasts of Korea, whereas $M$. hongae is primarily distributed on the south coast.

Where measurements are given, segments were measured along the midline (length) and at right angles to the midline at the widest part (width). Specimens recorded in this paper have been deposited in 


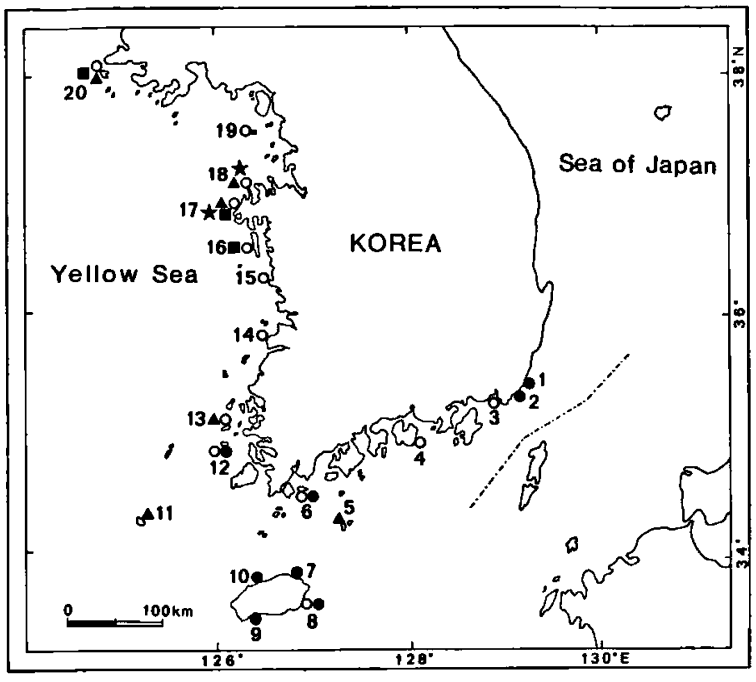

Fig. 1. Distribution of phoxocephalid amphipods in Korea ( 0 : Mandibulophoxus mai; $\bullet:$ M. hongae; $₫$ : Grandifoxus malipoensis; $\star$ : G. cuspis; - : G. bangpoensis). 1, Songjeong; 2, Haewundae; 3, Dadaepo; 4, Sangju; 5, Seodori, Geomundo; 6, Myeongsasimri, Sinjido; 7, Samyang; 8, Pyosun; 9, Hwasoon; 10, Ihori; 11, Jinri, Huksando; 12, Simok, Dochodo; 13, Gurimri, Bigumdo; 14, Byeonsan; 15, Chunjangdae; 16, Bangpo; 17, Malipo; 18, Hakampo; 19, Eulwangri, Yongyoodo; 20, Yongkipo, Baekryeongdo.

the collection of the Institute of Marine Sciences, National Fisheries University of Pusan (IMS) and the Zoölogisch Museum Amsterdam (ZMA).

\section{Taxonomic part}

Family PHOXOCEPHALIDAE G.O. Sars, 1891 Genus Mandibulophoxus Barnard, 1957

Diagnosis. - Eyes absent. Antenna 1: male with more aesthetascs than female, lacking calceoli; peduncle segment 2 shortened in both sexes. Antenna 2 , peduncle segment 1 not ensiform ( $=$ without cusp), segment 5 thin.

Mandibular molar not triturative, small, with 3 spines, without pubescence; palpar hump large; palp segment 2 as long as segment 3; right incisor with 5-6 teeth. Maxilla 1, inner lobe with 4 setae, palp 2-segmented. Maxilliped, inner lobe without dentiform spines, claw elongate, unguis distinct.

Coxal plate 1, anterodistal corner produced; posterior margin of plate 4 markedly expanded, narrowing medially. Coxal gills on gnathopod 2 to pereiopod 7 , gill on pereiopod 7 smallest. Oostegites on pereiopods 3 to 5 , sometimes a very small oostegite on gnathopod 2 occurs.

Gnathopods dissimilar, gnathopod 2 weakly elongate; carpus of gnathopod 1 ordinary to elongate, but cryptic and short in gnathopod 2; palms weakly or moderately oblique, propodus poorly setose anteriorly. Pereiopod 5, segment 2 broad form; segments 4-5 expanded posteriorly. Pereiopod 6, segments 2 and 4 broad, but segment 5 narrow; anteroproximal margin of male segment 2 hardly setose. Pereiopod 7 , segment 2 setose ventrally, segment 3 normal.

Epimeral plates 1-2 lack long posterior setae and midfacial setae above ventral facial ridge. Pleopod 3 smallest, peduncle of pleopods with 2 retinacula only, lacking accessory setae. Urosomite 3 without dorsal hook or process. Peduncle of uropods 1 and 2 with enlarged distolateral spine, inner ramus of uropod 2 provided with spines. Uropod 3 longer than uropod 1 or 2 , segment 2 of outer ramus elongate, both rami often more setose in male. Telson with 2-5 apical spines on each lobe plus setules, lacking dorsolateral spine group.

Remarks. - Male characters of the genus are recorded for the first time in this study. Unlike the diagnosis of the genus given by Barnard \& Drummond (1978), the Korean species of Mandibulophoxus bear spines or spinules on the dorsal margin of urosomite 1 and only a single facial seta on the peduncle segment 3 of antenna 2. They described this genus as having simple right lacinia mobilis and mid-apical spine on segment 6 of pereiopods 3-4, but in Korean species such structures were not observed. The number of apical spines on the outer plate of maxilla 1 was $11-12$ in Korean material (9 spines in Barnard \& Drummond, 1978).

A South African species, $M$. latipes Griffiths, 1976 shows features which are rather similar to the genus Basuto Barnard \& Drummond, 1978: a short inner ramus of uropod 2, a more enlarged gnathopod 2, an oblique row of setae across the third epimeral plate, and the presence of eyes, but the 


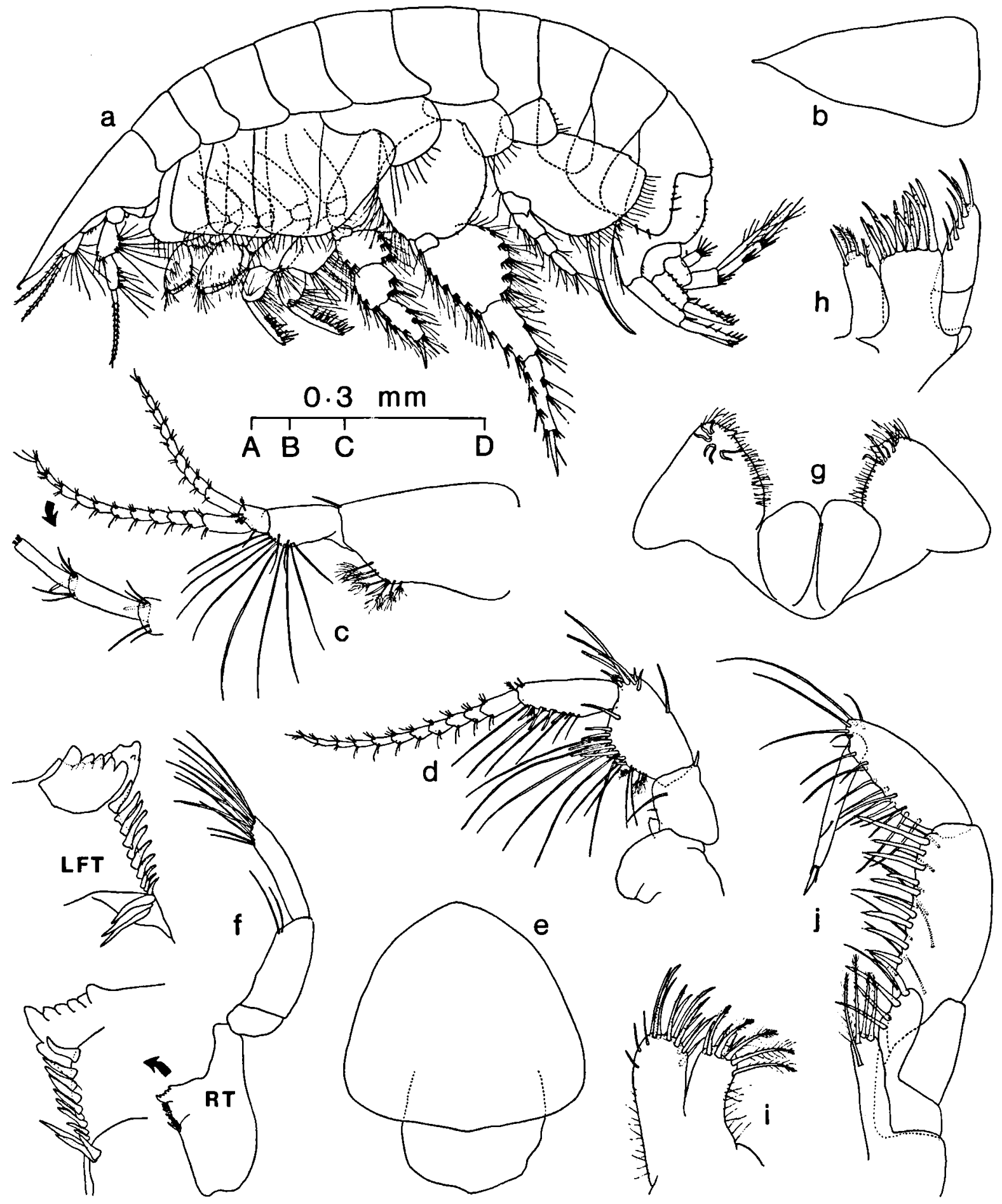

Fig. 2. Mandibulophoxus mai n. sp. ( 9 holotype $8.2 \mathrm{~mm}$ from Chunjangdae). a, entire animal, from the left; $\mathrm{b}$, dorsal view of head (scale AB); c, antenna 1 (AC); d, antenna 2 (AC); e, upper lip (AD); f, mandible (AC); g, lower lip (AD); h, maxilla 1 (AD); i, maxilla 2 (AD); j, maxilliped (AD). Each scale unit (AB, AC, $A D)$ represents $0.3 \mathrm{~mm}$. 

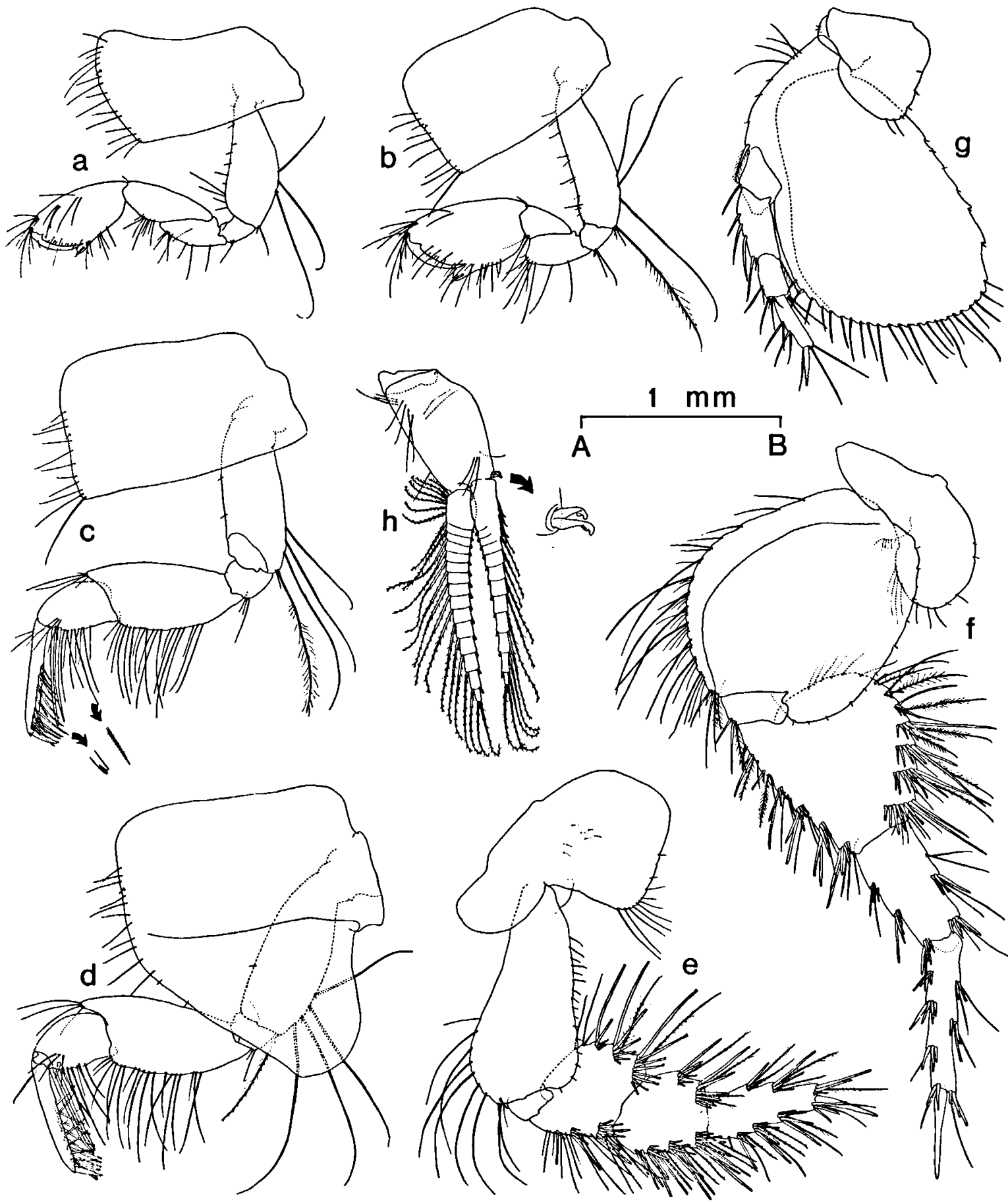

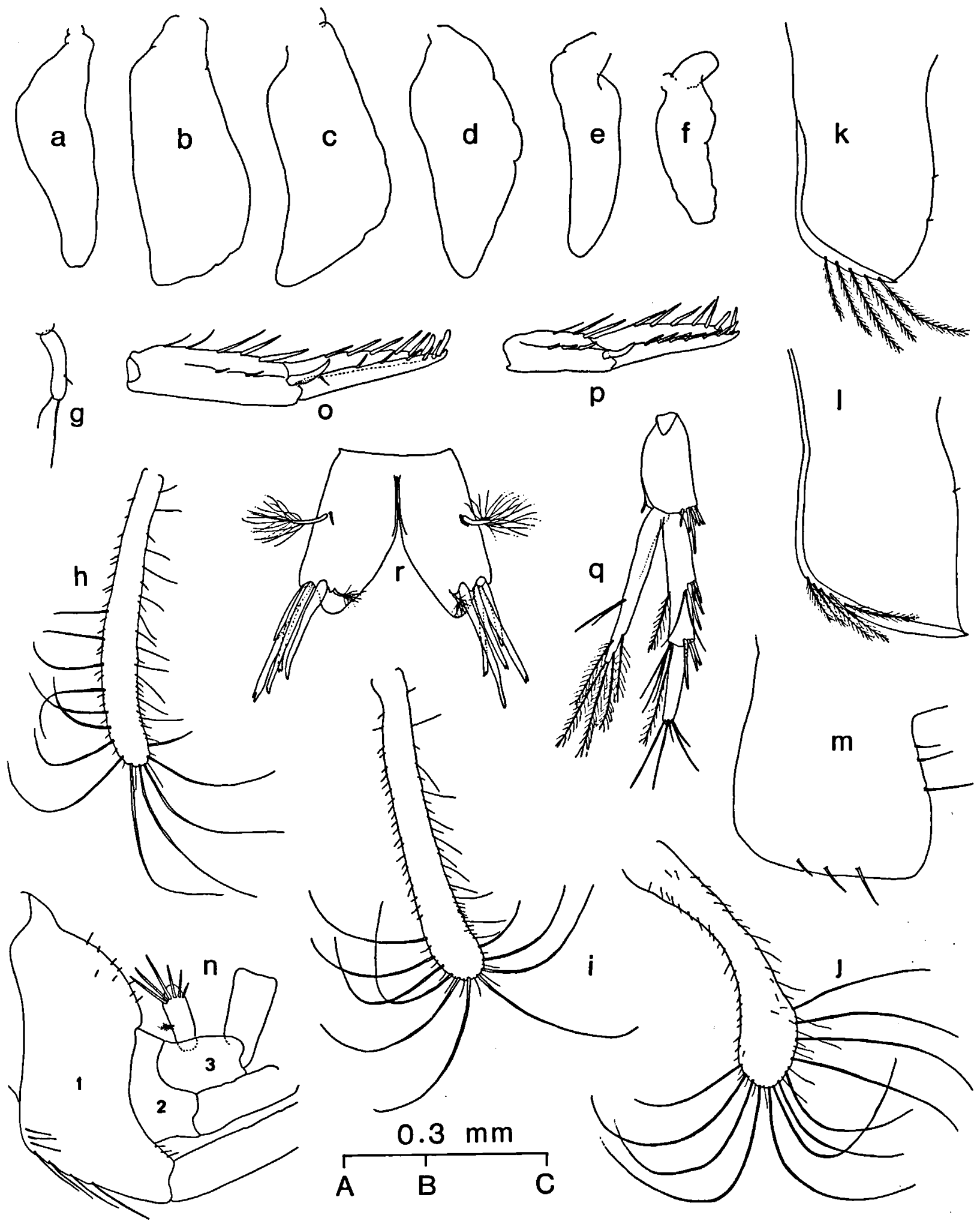
broadened segment 2 of pereiopod 5 is similar to Mandibulophoxus.

\section{Type-species: Mandibulophoxus gilesi Barnard, 1957}

Species content: $M$. uncirostratus (Giles, 1890); $M$. mai n. sp.; $M$. hongae n. sp.

Key to the known species of Mandibulophoxus.

1. Uropod 3, inner ramus less than half as long as segment 1 of outer ramus; uropod 2, outer ramus with 3-4 dorsal spines; pereiopods $3-4$, claw long, more than half the length of segment $6 \ldots \ldots \ldots \ldots \ldots \ldots \ldots \ldots \ldots \ldots \ldots . \ldots \ldots$

- Uropod 3, inner ramus more than $2 / 3$ as long as segment 1 of outer ramus; uropod 2 , outer ramus with 7-8 dorsal spines; pereiopods 3-4, claw short, less than $1 / 3$ the length

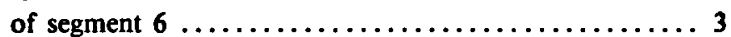

2. Gnathopod 1, carpus shorter than propodus; pereiopod 6, segment 6 about 1.5 times as long as segment 5 ; mandible, inner margin of palp segment 2 with 2 sets of setae ....... .................... uncirostratus (Giles, 1890)

- Gnathopod 1, carpus very long and thin, longer than propodus; pereiopod 6, segment 6 slightly longer than segment 5 ; mandible, inner margin of palp segment 2 with a single seta ............................. hongae $n$. sp.

3. Uropod 3, inner ramus shorter than segment 1 of outer ramus; pereiopods 5-6, posterior margin of segment 6 with 2 spine groups; epimeral plate 2, posterodistal corner rounded .......................... gilesi Barnard, 1957

- Uropod 3, inner ramus longer than segment 1 of outer ramus; pereiopods 5-6, posterior margin of segment 6 with 3 spine groups; epimeral plate 2, posterodistal corner pointed .... M. mai n. sp.

Mandibulophoxus mai n. sp. (figs. 2-5)

Material examined. - Prov. Chungnam, Seocheon-gun, Chunjangdae; 9 May 1986, 1 ovigerous \& holotype (ZMA Amph. 108.562), 1 ơ allotype (ZMA Amph. 108.563), 34 paratypes (ZMA Amph. 108.564), and 40 paratypes (IMS). Y.W. Jo coll.

Pusan, Dadaepo; 17 Apr. 1983, 7 ९ ९ (1 ovig.) and $7 \sigma^{\circ} \sigma^{\circ}$; 7 Mar. 1985, 3 ९ ९; 5 Apr. 1985, 1 ९. Y.W. Jo \& C. W. Ma coll.

Prov. Kyeongnam, Namhae-gun, Sangju; 25 May 1986, 2 \& \& (1 ovig.) and 4 ơ ơ. C.W. Ma coll.

Prov. Cheonnam, Wando-gun, Sinjido, Myeongsasimri; 11 May 1966, $7 \circ \circ$. Y.W. Jo coll.
Prov. Cheonnam, Sinan-gun, Dochodo, Simok; 6 Oct. 1986, 9 \& 9 (1 ovig.), $100^{\circ} \sigma^{\circ}$, and 4 juvs. K.C. Yoo coll.

Prov. Cheonnam, Sinan-gun, Bigumdo, Gurimri; 19 Oct. 1986, 1 ơ. S.J. Yoo coll.

Prov. Cheju, Namcheju-gun, Pyosun; 9 Aug. 1986, 4 \& ᄋ (1 ovig.) and $2 \circ \sigma$. Y.W. Jo \& M.Y. Hong coll.

Prov. Cheonbuk, Buan-gun, Byeonsan; 11 Aug. 1986, 1 \% and $1 \sigma$. C.W. Ma coll.

Prov. Chungnam, Seosan-gun, Bangpo; 20 Oct. 1986, 1 \&, 3 $\sigma \sigma$, and 4 juvs. Y.W. Jo \& H.J. Ko coll.

Prov. Chungnam, Seosan-gun, Malipo; 21 Oct. 1986, 320 specimens. Y.W. Jo coll.

Prov. Chungnam, Seosan-gun, Hakampo; 19 Oct. 1986, 75 specimens. Y.W. Jo coll.; 28 June 1987, 6 \& \& (4 ovig.) and 3 ○ $\%$. H.J. Ko coll.

Prov. Kyeongki, Ongjin-gun, Yongyoodo, Eulwangri; 27 Apr. 1986, 12 ९ ( 2 ovig.), $15 \sigma \sigma$, and 1 juv. Y.W. Jo coll.

Prov. Kyeongki, Ongjin-gun, Baekryeongdo, Yongkipo; 4 Nov. 1986, $1 \sigma^{\circ}$ and 2 juvs. B.S. Yeo \& M.S. Jo coll.

Description. - Largest female $8.5 \mathrm{~mm}$ (without antennae and telson), largest male $7.8 \mathrm{~mm}$. Female habitus is given in fig. $2 a$.

Female (holotype): Tip of rostrum bent downward, hook-shaped (fig. 2a), apicalmost sharply constricted in dorsal view (fig. $2 b$ ).

Antenna 1 (fig. 2c) short, a little exceeding rostrum; peduncle segment 1 stout, about 0.67 times as wide as long; segment 2 with long ventrodistal setae. Accessory flagellum 9-segmented; primary flagellum 11-segmented, bearing 1 short aesthetasc on segments 9 and 10 each; first segment of both flagellae elongate.

Antenna 2 (fig. 2d) with small gland cone; peduncle segment 3 with 1 facial seta plus ventral setule; flagellum 11-segmented, first segment longest.

Upper lip (fig. 2e) rounded triangular, as long as wide.

Mandibles (fig. 2f) with long palpar hump. Right incisor with 6 teeth, innermost tooth with hump inside; left incisor with 7 teeth. Right lacinia mobilis absent; left lacinia mobilis with 5 teeth. Right 9 rakers, left 10. Inner margin of palp segment 2 with 2 apical setae; segment 3 much more slender than segment 2.

Fig. 4. Mandibulophoxus mai n. sp. (Q holotype $8.2 \mathrm{~mm}$ from Chunjangdae). a-f, coxal gills on gnathopod 2 - pereiopod 7 (scale $A B) ; g-j$, oostegites on gnathopod 2 - pereiopod $5(A B) ; k-m$, epimeral plates $1-3$ (AB); $n$, urosomites (AB); 0-q, uropods 1-3 (AB); $r$, telson $(A C)$. Each scale unit $(A B, A C)$ represents $0.3 \mathrm{~mm}$. 

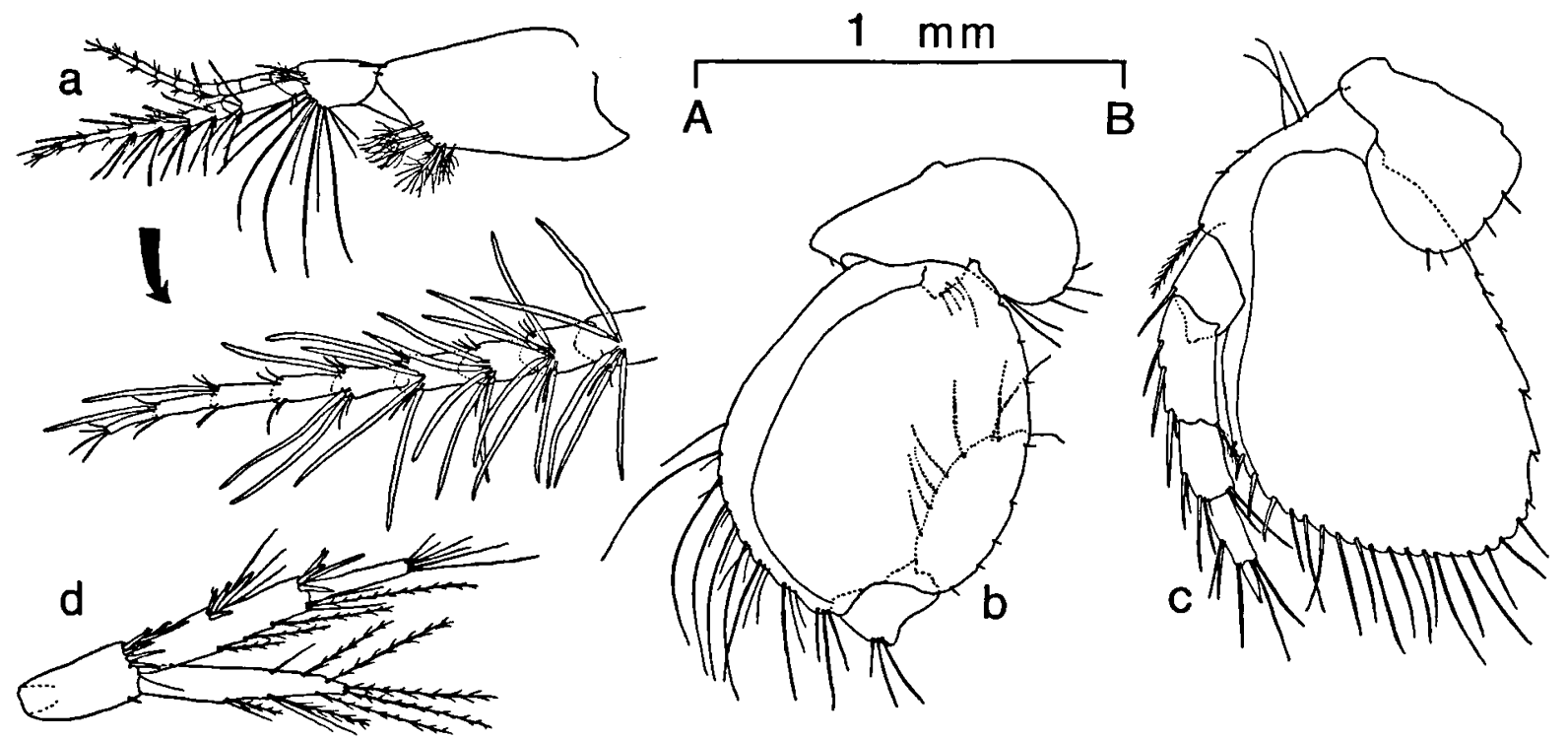

Fig. 5. Mandibulophoxus mai n. sp. ( $\sigma^{\circ}$ allotype $6.4 \mathrm{~mm}$ from Chunjangdae). a, antenna 1; b, proximal part of pereiopod 6; $\mathrm{c}$, pereiopod 7; d, uropod 3. Scales: all AB (=1 mm).

Lower lip (fig. $2 \mathrm{~g}$ ), outer lobe with lateral cone, 6-7 curled blades near distal end.

Maxilla 1 (fig. 2h), inner lobe with 3 plumose and 1 simple setae; left outer lobe with 12, right with 11 apical spines.

Maxilla 2 (fig. 2i), outer lobe wider than inner.

Maxilliped (fig. $2 \mathrm{j}$ ), outer lobe just reaching outer tip of palp segment 1 , with 4 inner marginal spines; palp segment 2 with 11 spines and several setae along the inner margin, segment 4 slightly longer than segment 3 , unguis relatively short, about 0.22 times as long as dactylus.

Coxal plates 1-4 (figs. $3 a-d)$ ): posterior margin of plates 1-3 not concave; ventral margin of plate 1 fully setose; ventral setae of plates 2-4 spread over about $2 / 3$ of ventral margin.

Gnathopod 1 (fig. 3a), carpus widest in the middle, with narrowly spread marginal setae, length ratio between anterior and posterior margins = 2.2:1 (or posterior margin much shorter than that of merus); propodus longer than carpus, palm oblique, palmar hump large but blunt.

Gnathopod 2 (fig. 3b), distalmost seta on posterior margin of basis plumose; carpus shorter than merus, with 2 setae on posterior margin; propodus larger than that of gnathopod 1, palm obli- que, palmar hump large.

Pereiopods 3 and 4 (figs. 3c,d), segment 6 slender, posterodistal margin with 8 outer and 7 inner spines, all spines bifid, accessory bud slightly longer than main spine; claw short, about $1 / 4$ the length of segment 6 .

Pereiopod 5 (fig. 3e), anterodistal margin of segment 2 with widely spread setae (about half the total margin); segment 4 with 3 spine groups on both anterior and posterior margins; segment 5 with 4 and 2 spine groups; segment 6 with 5 and 3 spine groups; width ratios of segments 2,4,5,6=80:71: $60: 35$, length ratios $=160: 62: 70: 85$. Claw about 0.6 times as long as segment 6 .

Pereiopod 6 (fig. 3f), segment 2 broadened distally, anteroproximal margin poorly setose but not bare; posteroproximal margin of segment 4 setose; number of spine groups on anterior and posterior margins =7:7 (segment 4), 3:2 (segment 5), 4:3 (segment 6). Width ratios of segments $2,4,5,6=$ $152: 112: 50: 25$, length ratios $=183: 128: 100: 120$. Claw about 0.56 times as long as segment 6 .

Pereiopod 7 (fig. $3 \mathrm{~g}$ ), posterior margin of coxal plate with 6 setae; segment 2 distally widened, posteroventral corner produced, ventral margin densely setose (24 long setae). Length ratios of seg- 
ments 2,4,5,6=185:54:37:45; claw long, about 0.67 times as long as segment 6 .

Pleopod 1 (fig. $3 \mathrm{~h}$ ), outer ramus about 1.7 times as long as peduncle, inner ramus 11-segmented, outer 14-segmented. Peduncle of pleopod 2 subequal to that of pleopod 1. Peduncle of pleopod 3 shorter than those of pleopods 1-2.

Coxal gills on pereiopods 3 to 5 (figs. $4 b-d$ ) large, those on gnathopod 2, pereiopods 6 and 7 (figs. $4 \mathrm{a}, \mathrm{e}, \mathrm{f}$ ) small, the latter bilobate.

Oostegites on gnathopod 2 to pereiopod 5 (figs. $4 \mathrm{~g}-\mathrm{j}$ ), linear, that on gnathopod 2 minute, those on pereiopods $3-5$ bearing numerous setules and long setae.

Epimeral plates $1-3$ (figs. $4 \mathrm{k}-\mathrm{m}$ ): plate 1 narrowest, posterodistal corner slightly pointed, ventral margin with 5 plumose setae; plate 2 , posterodistal corner pointed, anteroventral margin with 5 setae; plate 3 widest, ventral margin with 3 spines.

Pleosomite 3 with a few spinules on posterodorsal margin. Urosomite 1 (fig. 4n), dorsal margin with several spinules (or setules), posterodistal margin with 3 spinules, anteroventral margin with 7 setae.

Uropod 1 (fig. 4o), outer margin of peduncle with 2 small spines and 1 enlarged apicolateral spine, inner margin with 2 thin and 3 large spines; inner ramus about 0.9 times as long as outer ramus, with 6 dorsal spines and 1 ventrolateral spine, outer ramus with 6 dorsal spines, apicalmost spines on both rami thick and blunt.

Uropod 2 (fig. $4 \mathrm{p}$ ), peduncle about 0.82 times as long as rami, outer margin with 3 short spines plus 1 enlarged apicolateral spine, inner margin with 1 slender and 2 large spines; inner and outer rami subequal in length, inner ramus with 6 , outer with 8 dorsal spines.

Uropod 3 (fig. 4q), inner ramus long, longer than segment 1 of outer ramus, with 5 lateral and 2 apical setae; outer ramus, lateral margin of segment 1 with 2 groups of long spines, segment 2 about $\mathbf{0 . 6}$ times as long as segment 1 , with 5 apical setae.

Telson (fig. 4r), apices bevelled, each lobe with 5 long apical spines plus setule, longest spine about 0.8 times of telson length.

Male: Antenna 1 (fig. 5a), primary flagellum 9-segmented, aesthetascs larger and more numerous than in female, number of aesthetascs on segments $1-8=5-6-5-4-3-0-1-1$, respectively.

Pereiopod 5, narrow patch of setation on anterodistal margin of segment 2 (about $35 \%$ of total margin).

Pereiopod 6 (fig. 5b), anteroproximal margin of segment 2 naked, posteroproximal margin of segment 4 setose.

Pereiopod 7 (fig. 5c), length of segment 5 subequal to segment 6 .

Uropod 3 (fig. 5d) more setose than in female, inner ramus with 9 lateral and 2 apical setae; outer ramus, medial margin of segment 1 with 3 plumose setae, lateral margin with 2 groups of long spines.

Remarks. - Mandibulophoxus mai resembles the North American species $M$. gilesi in the short claw of pereiopods 3-4, the long inner ramus of uropod 3 , and the distally broadened segment 2 of pereiopod 7. However, the new species differs from the latter in the pointed posterodistal corner of epimeral plates $1-2$, the lower number of teeth on the left lacinia mobilis ( 5 in the former, 6-8 in the latter), and having more spine groups on the posterior margin of segment 6 of pereiopods 5-6.

$M$. mai can be easily distinguished from the other Korean species $M$. hongae by the following characters: the shorter carpus of the gnathopods, the short claw of pereiopods 3-4, the shape of the spines on segment 6 of pereiopods 3-4, the high number of spine groups on the posterior margin of segment 6 of pereiopods 5-6, the setose proximoposterior margin of segment 4 of pereiopod 6 , the distally broadened segment 2 of pereiopod 7, the pointed posterodistal corner of epimeral plates $1-2$, the longer inner ramus of uropod 3, and the presence of an oostegite on gnathopod 2.

Morphological variations among populations of this species are rather small. The number of inner setae on the mandibular palp segment 2 is variable from 2 to 5 regardless of size, but in general male specimens show fewer setae (usually 2 ). The relative length of the unguis of maxillipedal palp segment 4 is also variable from 0.2 to 0.45 times the length of dactylus. Some animals bear a heavy spine on the posteroventral margin of epimeral plate 2 . 


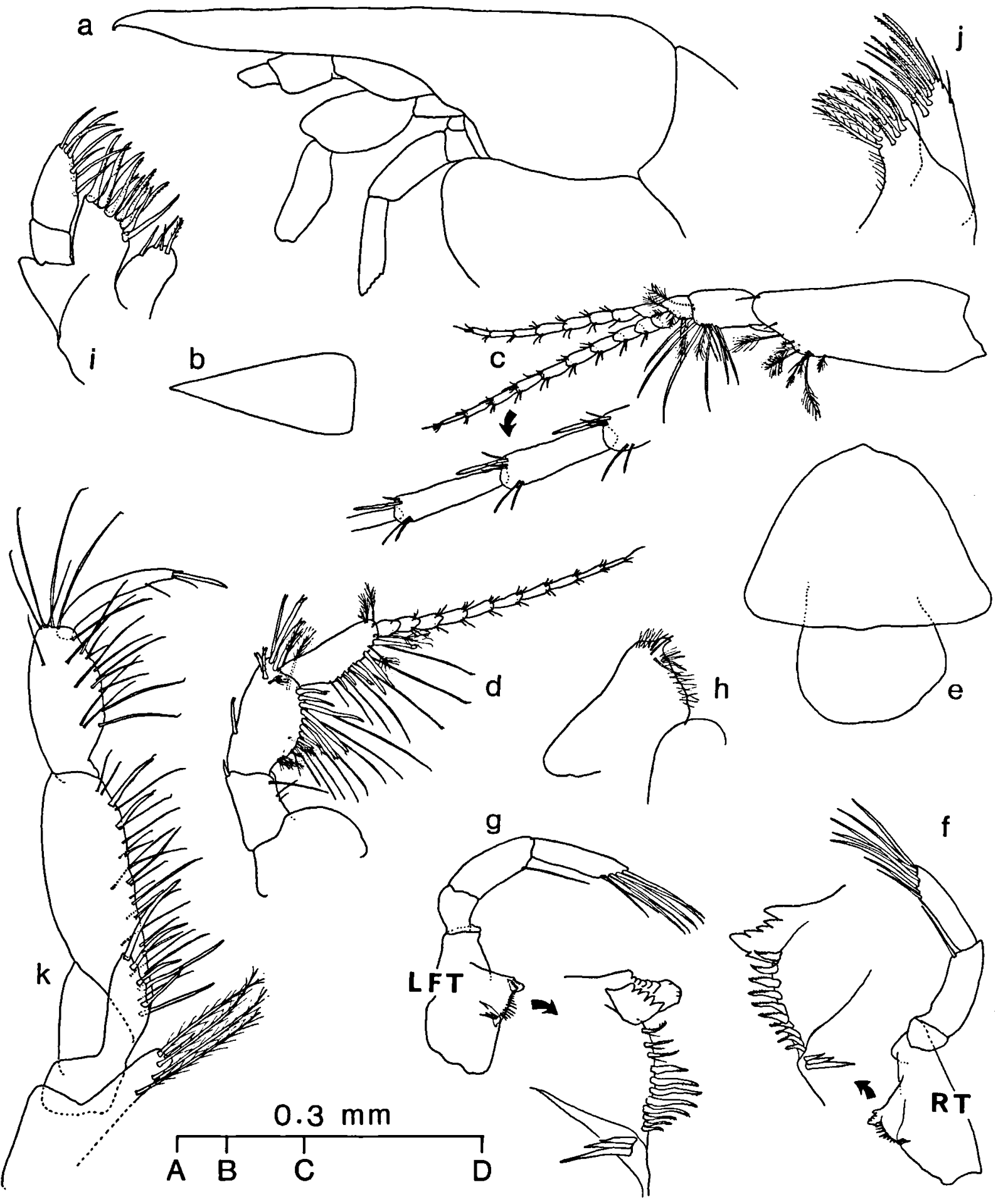

Fig. 6. Mandibulophoxus hongae $\mathrm{n}$. sp. ( 9 holotype $6.2 \mathrm{~mm}$ from Haewundae). a, head (scale AC); b, head, dorsal view (AB); c, antenna 1 (AC); d, right antenna 2 (AC); e, upper lip (AD); f, right mandible (AC); g, left mandible (AC); h, lower lip (AD); i, maxilla 1 (AD); j, maxilla 2 (AD); $k$, maxilliped (AD). Each scale unit (AB, AC, AD) represents $0.3 \mathrm{~mm}$. 


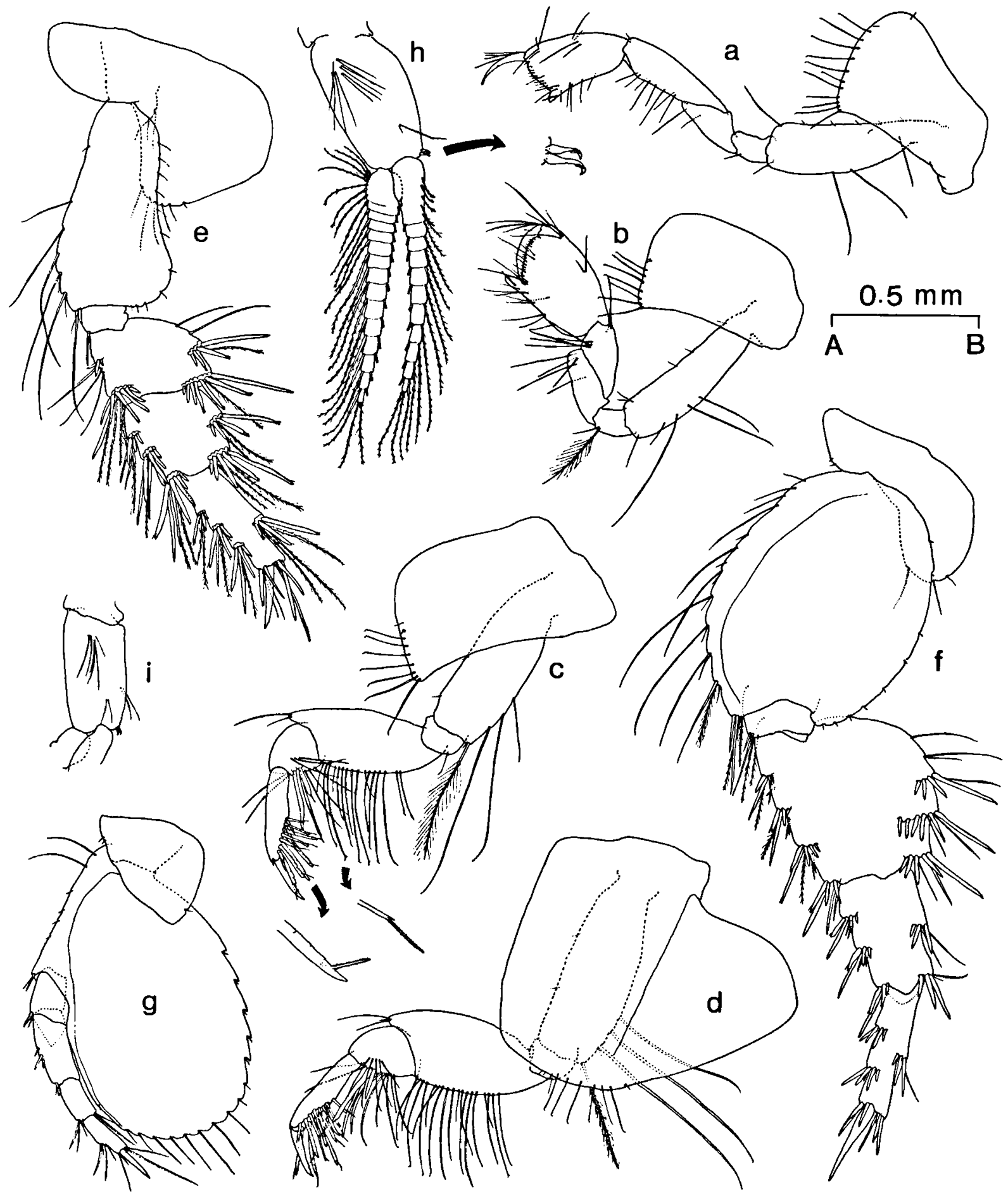

Fig. 7. Mandibulophoxus hongae $\mathrm{n}$. sp. ( $Q$ holotype $6.2 \mathrm{~mm}$ from Haewundae). a, gnathopod 1; b, gnathopod 2; c, pereiopod 3; d, pereiopod 4; e, pereiopod 5; f, pereiopod 6; g, pereiopod 7; h, pleopod 1; i, peduncle of pleopod 3. Scales: all AB $(=0.5 \mathrm{~mm})$. 
Major sexual dimorphism is confined to antenna 1, pereiopod 6, and uropod 3. Male specimens show increased size and a higher number of aesthetascs on the primary flagellum of antenna 1 , a naked anteroproximal margin of segment 2 of pereiopod 6 , and more setose rami of uropod 3 (figs. 5a, b, d). Another difference can be found in male pereiopod 7 (short segment 6) (fig. 5c).

Etymology. - Named after Mr. Chae Woo Ma, who assisted the author during the fieldwork for several years.

Distribution and ecology. - The new species is widely distributed on sandy bottoms along the west and the south coasts of Korea (fig. 1). In some localities (Dochodo, Sinjido and Sehwa) this species is sympatric with $M$. hongae.

Compared with the other species of the genus, males of $M$. mai were commonly collected during the present study from intertidal to shallow-water samples up to $100 \mathrm{~cm}$ deep (males of $M$. gilesi and $M$. uncirostratus are unknown).

Ovigerous females were collected in April-June, August, and October. The holotype $(8.2 \mathrm{~mm}$, May 1986) carried 2 eggs, sized $0.32 \times 0.45 \mathrm{~mm}$, and a female (8.5 mm, June 1987) from Hakampo carried 16 eggs, sized $0.58 \times 0.77 \mathrm{~mm}$.

\section{Mandibulophoxus hongae n. sp. (figs. 6-9)}

Material examined. - Pusan, Haewundae; 24 June 1986, 1 ovigerous $\$$ holotype (ZMA Amph. 108. 565) and 3 ovigerous \& paratypes (IMS); 12 Mar. 1986, 37 (33 ovig.) paratypes (ZMA Amph. 108. 566) and 37 (33 ovig.) paratypes (IMS); 13 Apr. 1986, 1 ovigerous 9 paratype (IMS). Y.W. Jo \& M.Y. Hong coll.

Prov. Cheju, Bukcheju-gun, Ihori; 7 May 1986, 8 \& (6 ovig.) and $4 \sigma^{\circ}$ paratypes (ZMA Amph. 108.567) and $8 \%$ (6 ovig.), 4 $\sigma$ and 3 juv. paratypes (IMS). Students of the Department of Marine Biology, NFUP coll.

Pusan, Songjeong; 30 Mar. 1986, 3 ९ ९. Y.W. Jo \& M.Y. Hong coll.

Prov. Cheonnam, Wando-gun, Sinjido, Myeongsasimri; 11 May 1986, 4 ovigerous $\$$ \&. Y.W. Jo coll.

Prov. Cheju, Bukcheju-gun, Samyang; 7 Aug. 1986, 11 \& (2 ovig.) Y.W. Jo \& M.Y. Hong coll.

Prov. Cheju, Namcheju-gun, Pyosun; 9 Aug. 1986, 1 \&. Y.W. Jo \& M.Y. Hong coll.

Prov. Cheju, Namcheju-gun, Hwasoon; 8 Aug. 1986, 8 \&

(1 ovig.). Y.W. Jo \& M.Y. Hong coll.

Prov. Cheonnam, Sinan-gun, Dochodo, Simok; 6 Oct. 1986,
4 ९ (2 ovig.). K.C. Yoo coll.

Description. - Body length of female and male up to $7.0 \mathrm{~mm}$ and $4.2 \mathrm{~mm}$, respectively.

Female (holotype): Rostrum bent downward (fig. 6a), long triangle shape in dorsal view (fig. 6b).

Antenna 1 (fig. 6c), peduncle segment 1 about 0.42 times as wide as long; segment 2 , ventrodistal setae relatively short. Accessory flagellum 8-segmented; primary flagellum 10-segmented, segments 7-9 each with a short aesthetasc, first segment of both flagellae short.

Antenna 2 (fig. 6d), peduncle segment 3 with 1 facial seta plus 1-2 ventral setule(s); flagellum 10-segmented, first segment not elongate.

Upper and lower lips (figs. 6e,h) similar to $M$. mai, but upper lip less rounded, wider than long; lateral cone on the outer lobes of lower lip long and sharp.

Mandibles (figs. 6f,g): palpar hump medium, right incisor 5-dentate, innermost tooth with an additional denctile inside, left incisor with 7 teeth; right lacinia mobilis absent, left lacinia mobilis with 5 teeth; right 10 rakers, left 11 . Palp segment 2 with single inner apical seta.

Maxilla 1 (fig. 6i), inner lobe with 1 plumose and 3 simple setae, outer lobe with 11 apical spines.

Maxilla 2 (fig. 6j), inner lobe shorter than, but as wide as, outer lobe.

Maxilliped (fig. 6k), outer lobe somewhat exceeding outer tip of palp segment 1 , with 6 long inner marginal spines; inner margin of palp segment 2 with many setae and distally 2 spines; segment 4 longer than segment 3 , unguis thin and long, about 0.4 times as long as dactylus.

Coxal plates 1-4 (figs. 7a-d): posterior margin of plates $1-3$ concave, widened distally, ventral setae of plates 2-4 occupying 1/2 of ventral margin.

Gnathopod 1 (fig. 7a) slender, carpus markedly elongate, length of posterior margin subequal to that of merus, posterior margin with widely spread setae; propodus much shorter than carpus, palm weakly oblique, palmar hump large and sharp.

Gnathopod 2 (fig. 7b), distalmost seta on posterior margin of basis simple and short, not plumose; one of distal setae on ischium long and plumose; 


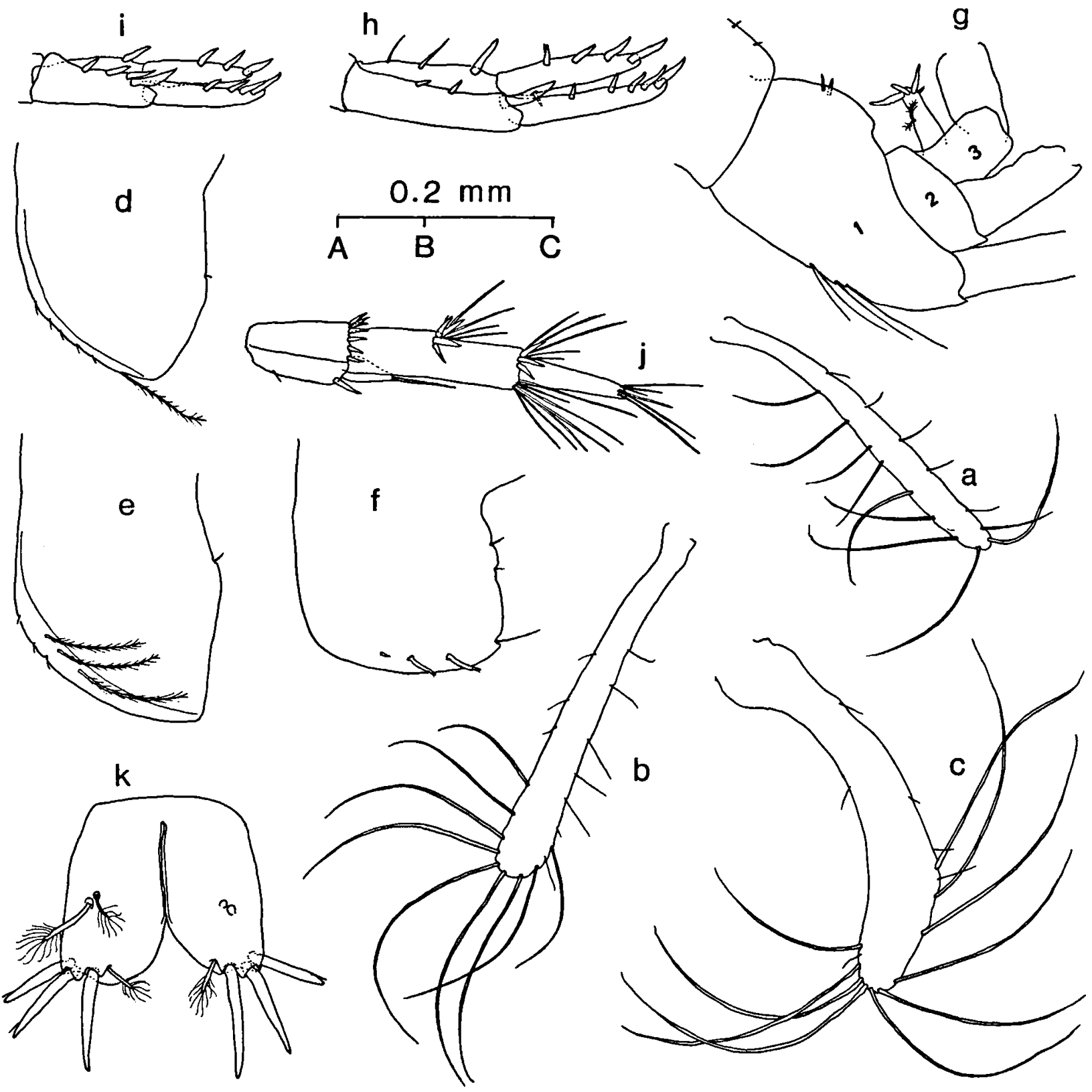

Fig. 8. Mandibulophoxus hongae n. sp. ( 9 holotype $6.2 \mathrm{~mm}$ from Haewundae). a, oostegite on pereiopod 3 (scale AB); b, oostegite on pereiopod $4(A B)$; c, oostegite on pereiopod $5(A B)$; d, epimeral plate $1(A B)$; e, epimeral plate 2 (AB); f, epimeral plate 3 ( $A B$ ); g, urosomites (AB); h, uropod $1(A B)$; i, uropod $2(A B) ; j$, uropod $3(A B)$; $k$, telson ( $A C)$. Each scale unit $(A B, A C)$ represents 0.2 mm.

carpus of the same length as merus, with 5 setae on posterior margin; palm weakly oblique, palmar hump large and sharp.

Pereiopods 3 and 4 (figs. 7c,d): segment 6 stout, posterodistal part with 7-8 outer and 6 inner marginal spines, all spines bifid, with accessory bud much elongated and barbed; claw long, more than half the length of segment 6 .

Pereiopod 5 (fig. 7e), anterodistal margin of segment 2 setose about half the total margin; segment 4 with 2 spine groups on both anterior and posterior margins; segment 5 with 3 and 2 spine groups; seg- 

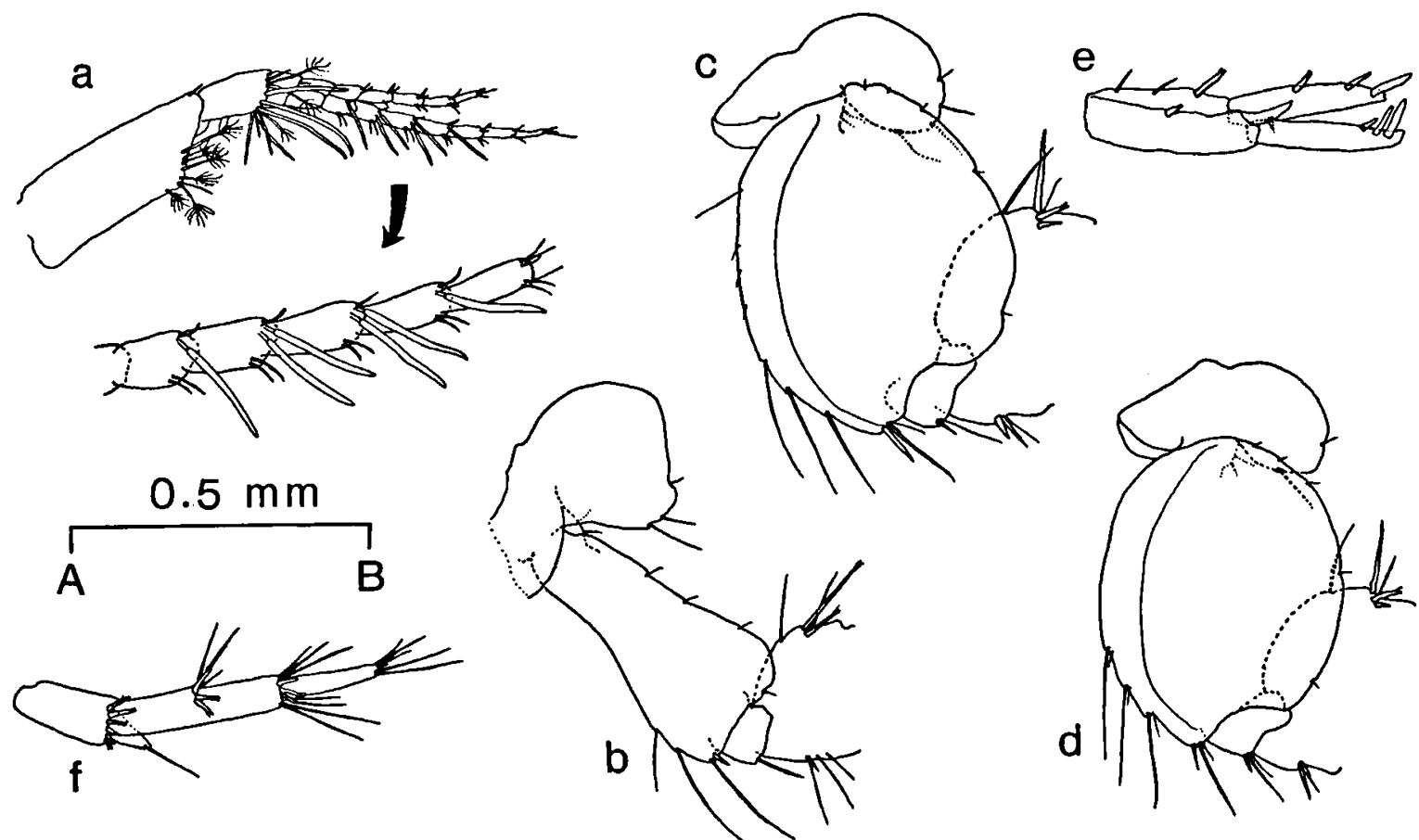

Fig. 9. Mandibulophoxus hongae n. sp. (a-c, e, f, o paratype $4.2 \mathrm{~mm}$; d, o paratype $3.6 \mathrm{~mm}$, from Ihori). a, antenna 1; b, proximal part of pereiopod 5; $c-d$, proximal part of pereiopod 6; e, uropod 1; f, uropod 3. Scales: all $A B(=0.5 \mathrm{~mm})$.

ment 6 with 4 and 2 spine groups; claw less than half the length of segment 6; width ratios of segments 2,4,5,6=57:53:45:25, length ratios $=107: 40: 45: 65$.

Pereiopod 6 (fig. 7 f) poorly setose, segment 2 distally narrowing, anteroproximal margin moderately setose; posteroproximal margin of segment 4 bare; number of spine groups on anterior and posterior margins =4:3 (segment 4), 3:2 (segment 5), 3:2 (segment 6). Width ratios of segments $2,4,5,6=102: 78: 40: 18$, length ratios $=136: 82: 66$ : 72. Claw about 0.6 times as long as segment 6 .

Pereiopod 7 (fig. $7 \mathrm{~g}$ ), posterior margin of coxal plate with single setule; segment 2 distally narrowing, ventral margin with 10 setae; length ratios of segments $2,4,5,6,7=135: 37: 22: 27: 20$.

Pleopod 1 (fig. $7 \mathrm{~h}$ ), outer ramus about 1.8 times as long as peduncle, inner ramus 10-segmented, outer 14-segmented. Pleopod 2 similar to pleopod 1. Peduncle of pleopod 3 (fig. 7i) much smaller than that of pleopod 1 or 2 .

Oostegites on pereiopods 3 to 5 (figs. $8 \mathrm{a}-\mathrm{c}$ ), number of setules small.
Epimeral plates 1 to 3 (figs. $8 \mathrm{~d}-\mathrm{f}$ ) subequal in width, with rounded posterodistal corner; ventral margin of plate 1 oblique, with 1 plumose seta and 5 setules; ventral margin of plate 2 with 3 anterior setules and 3 submarginal plumose setae; plate 3 with 3 spines on ventral margin.

Pleosomites $1-3$ with a few dorsal spinules each. Dorsal margin of urosomite 1 (fig. $8 \mathrm{~g}$ ) with 2 spines, posterodistal margin without spinules, ventral margin with 4 setae.

Uropod 1 (fig. 8h), outer margin of peduncle with 2 small stout spines and 1 enlarged apicolateral spine, inner margin with 2 thin and 1 thick spines; inner ramus shorter than outer, with 4 stout dorsal spines and 1 ventrolateral spine; outer ramus with 5 dorsal spines; apicalmost spine on both rami largest.

Uropod 2 (fig. 8i), length of peduncle subequal to rami, outer margin with 3 spines plus enlarged apicolateral spine, inner margin with single spine; inner ramus slightly shorter than outer, outer ramus with 4, inner with 3 dorsal spines. 
Uropod 3 (fig. 8j), inner ramus very small, about $1 / 3$ of length of segment 1 of outer ramus, with single apical seta; outer ramus, lateral margin of segment 1 with 2 groups of short spines, segment 2 about 0.66 times as long as segment 1 , with 6 apical setae.

Telson (fig. 8k) wider than long, apices not protuberant medially, each lobe with 3 apical spines plus plumose setule, longest spine about 0.6 times as long as telson length.

Male: Antenna 1 (fig. 9a), primary flagellum of 8 segments, aesthetascs longer and more numerous than in female, number of aesthetascs on segments $2-5=1-2-2-1$, respectively.

Gnathopod 1, carpus elongate, length of anterior margin subequal to propodus, posterior margin about the same length as merus.

Pereiopod 5 (fig. 9b), segment 2 strongly broadened distally, anterior margin setose in about distal fourth only.

Pereiopod 6 (fig. 9c), anteroproximal margin of segment 2 sparsely setose, with 1 long and 3 setules; posteroproximal margin of segment 4 naked.

Pereiopod 7, length of segment 5 equal to segment 6.

Pleopods 1-3: peduncles rather stout, outer ramus of pleopod 1 about 1.3 times as long as peduncle, pleopod $3=1.5$ times.

Uropod 1 (fig. 9e), outer ramus with 3 dorsal spines which are closely set on distal part.

Uropod 3 (fig. 9f) similar to that of female.

Remarks. - The very long and slender carpus of gnathopod 1 (especially in the female) is a most peculiar character of $M$. hongae. The species is similar to the Indian species $M$. uncirostratus in the slender peduncle segment 1 of antenna 1 , the long claw of pereiopods $3-4$, the distally narrow segment 2 of pereiopod 7, and the short inner ramus of uropod 3. The new species, however, differs from $M$. uncirostratus by the following features: the long carpus of the gnathopods, the length of segment 4 of pereiopod 5 (segment 4 much shorter than 5 in $M$. uncirostratus), and a relatively short segment 6 of pereiopod 6 (for the illustrations and descriptions of the latter see Giles, 1890; Pillai,
1957; Nayar, 1959).

Specimens from the western part of the south coast including Cheju Island have narrowly spread dorsal spines on the outer ramus of uropod 1 (fig. 9e), whereas specimens, with the exception of juveniles, from the type-locality and Songjeong show more widely spread dorsal spines. Generally, the length of mandibular palp segments $\mathbf{2}$ and $\mathbf{3}$ are subequal to each other, but some animals have longer segment 2 regardless of their size or sex.

Male specimens of this species were collected only at Ihori beach. Males can be distinguished from females by the antenna 1 richly provided with large aesthetascs, the naked (fig. 9d) or poorly setose anteroproximal margin of segment 2 of pereiopod 6, and the short segment 6 of pereiopod 7 (equal in length to segment 5 ).

Etymology. - This species is named for my wife, Mu Young Hong, for her endless encouragement on my studies and for ably assisting with the fieldwork.

Distribution and ecology. - The new species was found along the south coast of the country (fig. 1). The substrate at Haewundae, Songjeong, and Sinjido consisted of medium to coarse sand, but that of the remaining localities of fine sand.

During the study ovigerous females were collected in March through October. The holotype (6.2 $\mathrm{mm}$ ) carried 7 eggs, sized $0.33 \times 0.46 \mathrm{~mm}$.

\section{Genus Grandifoxus Barnard, 1979}

Diagnosis. - Rostrum constricted. Eyes present. Antenna 1, peduncle segment 2 ordinary to elongate. Antenna 2, peduncle segment 1 ensiform, segment 3 with 3 or more facial setae, segment 4 with 2 or 3 groups of facial spines plus 1 long ventrodistal spine, segment 5 with 1 or 2 groups of facial spines plus 3 ventrodistal spines, ventral margin of segments 4-5 densely setose with long and short setae.

Mandibular molar not triturative, bearing 4-10 spines, usually bearing pubescence; right incisor with 3 teeth, left with 2 widely spaced teeth, outer 
tooth with 2 terminal bumps; right lacinia mobilis bifid, left with 4 teeth (rarely 5); palp segments 2 and 3 subequal in length. Maxilla 1 , inner lobe with 4 setae, palp of 2 segments. Maxilliped, inner lobe with 2 dentiform spines; outer lobe long, exceeding end of palp segment 1; claw elongate, unguis mostly immersed, short.

Coxal plates 1-3, posteroventral corner with or without cusp, with narrowly spread setae; plate 4 parallel, not expanded posteriorly. Coxal gills on gnathopod 2 to pereiopod 7 , gill on pereiopod 7 smallest, not bilobate. Oostegites on gnathopod 2 to pereiopod 5, linear. Gnathopods small, similar; propodus setose anteriorly. Pereiopods 3-4, posterodistal margin of segment 5 with a few thick and long setae plus a number of thin setae. Pereiopods 5 and 6 densely setose and spinose, segments 4-5 broad; segment 2 of pereiopod 5 of broad form. Pereiopod 7, segment 2 almost naked ventrally.

Epimeral plates 1-3, posterodistal corner not pointed, bearing numerous long posterior setae. Pleopods 1-3, peduncle with 2 retinacula plus 1-2 accessory setae, outer ramus with 4-8 more segments than inner ramus. Urosomite 1 with or without lateral facial spines and ventral setae. Urosomite 3 with or without lower posterior spines, dorsal hook absent. Uropod 1, peduncle with or without enlarged apicomedial spine. Uropod 2, peduncle with 1-3 inner marginal spines, inner ramus with or without dorsal spines. Rami of uropods 1-2 with apical nails, no rami continuously spinose to apex. Uropod 3 relatively short, segment 2 of outer ramus minute, bearing 1-3 apical setae. Telson with 1-6 apical spines plus setules on each lobe, dorsolateral surface with spine and setule groups.

Remarks. - As Barnard (1980), Barnard \& Barnard (1982) and Coyle (1982) mentioned, the genus Grandifoxus is very similar to Rhepoxynius Barnard, 1979 and Foxiphalus Barnard, 1979: Grandifoxus is only distinguished from the latter two genera by having more than 3 facial setae on the peduncle segment 3 of antenna 2, a constricted rostrum (unconstricted in Foxiphalus), and dorsolater- al spine groups on the telson lobes (lacking in Rhepoxynius). Since the generic distinctions among the above mentioned genera are too weak, it is expected that further refinements might allow one to merge some of these genera.

Type-species. - Phoxus grandis Stimpson, 1856 (=Pontharpinia milleri Thorsteinson, 1941).

Species content. - G. longirostris (Gurjanova, 1938); G. lindbergi (Gurjanova, 1953); G. aciculata Coyle, 1982; G. acanthinus Coyle, 1982; G. vulpinus Coyle, 1982; G. malipoensis n. sp.; G. cuspis n. sp.; G. bangpoensis n. sp.

Key to the known species of Grandifoxus ${ }^{*}$

1. Antenna 2, peduncle segment 3 with less than 5 facial setae; urosomite 1 lacking lateral facial setae or spines; coxal plates 1-3 without posteroventral cusp; uropod 3, lateral spines on segment 1 of outer ramus in pairs $\ldots \ldots \ldots \ldots \ldots \ldots 2$

- Antenna 2, peduncle segment 3 with more than 7 facial setae; urosomite 1 with lateral facial setae or spines; coxal plates 1-3 with posteroventral cusp; uropod 3, lateral spines on segment 1 of outer ramus in triads or more .........6 6

2. Uropod 1, peduncle with enlarged apicomedial spine ... 3

- Uropod 1, peduncle without enlarged apicomedial spine 5

3. Antenna 2, peduncle segment 4 with 3 groups of facial spines; urosomite 3 lacking lower posterior spines; uropod 1, inner ramus with a short and stout proximoventral spine ...... ............... G. longirostris (Gurjanova, 1938)

- Antenna 2, peduncle segment 4 with 2 groups of facial spines; urosomite 3 with a few lower posterior spines; uropod 1 , inner ramus with a long and thin proximoventral seta ..... 4

4. Antenna 2, peduncle segment 4 with dorsal spines; pereiopod 5 , posterior margin of segment 6 lacking central spine group, distal spines only .......... G. bangpoensis $\mathrm{n}$. $\mathrm{sp}$.

- Antenna 2, peduncle segment 4 without dorsal spines; pereiopod 5 , posterior margin of segment 6 with central spine group plus distal spine group ........ G. aciculata Coyle, 1982

5. Uropods 1-2, spines on rami long and narrow; uropod 1 , inner ramus with proximomedial seta; urosomite 3 with long and thin posteroventral spines . G. acanthinus Coyle, 1982

- Uropods 1-2, spines on rami short and stout; uropod 1, inner ramus without proximomedial seta; urosomite 3 with short and stout posteroventral spines .. G. vulpinus Coyle, 1982

6. Antenna 2, dorsal margin of peduncle segment 4 with setae only; pereiopod 5, posterior margin of segment 6 lacking spine groups ......... G. lindbergi (Gurjanova, 1953)

- Antenna 2, peduncle segment 4 with dorsal spines; pereiopod 5 , posterior margin of segment 6 with 3-4 spine groups 7

7. Uropod 2, inner ramus with 2 dorsal spines; uropod 3 , inner ramus equal to or longer than segment 1 of outer ramus; pereiopod 7, segment 2 narrowing distally, ventral margin 
rounded $\ldots \ldots \ldots \ldots \ldots \ldots$ G. grandis (Stimpson, 1856)

- Uropod 2, inner ramus lacking dorsal spines; uropod 3, inner ramus shorter than segment 1 of outer ramus; pereiopod 7 , segment 2 widened distally, ventral margin straight ... 8

8. Coxae 1-3, posteroventral corner with strong cusp; pereiopod 6 , segments 4 and 5 with 4 and 3 mid-facial spine groups, respectively; pereiopod 7 , posterodistal corner of segment 2 markedly pointed ................ G. cuspis n. sp.

- Coxae 1-3, posteroventral corner with small cusp; pereiopod 6 , segments 4 and 5 with 2 and 1 mid-facial spine groups, respectively; pereiopod 7 , posterodistal corner of segment 2 not strongly pointed ...........G. malipoensis $\mathbf{n}$. sp.

* G. nasuta (Gurjanova, 1936) (see Coyle, 1982) is omitted from this key because the species does not agree with the main diagnosis of the genus Grandifoxus, viz., having 1 or 2 facial seta(e) on peduncle segment 3 of antenna 2, lacking dorsolateral spine groups on the telson lobes (Coyle, 1982: 446; Gurjanova, 1936: $250 ; 1951: 382$ ), and only 2 strong spines on the mandibular molar (Gurjanova, 1936: 250; Barnard, 1980: 495).

Grandifoxus malipoensis n. sp. (figs. 10-12)

Material examined. - Prov. Chungnam, Seosan-gun, Malipo; 21 Oct. 1986, 1 q holotype (ZMA Amph. 108. 568), 3 \% paratypes (ZMA Amph. 108.569), and 4 $\&$ paratypes (IMS). Y.W. Jo coll.

Prov. Kyeongki, Ongjin-gun, Baekryeongdo, Yongkipo; 4 Nov. 1986, 3 \& $\%$. B.S. Yeo \& M.S. Jo coll.

Prov. Chungnam, Seosan-gun, Hakampo; 19 Oct. 1986, 3

$Q \varphi$ and 1 juv. Y.W. Jo coll.

Prov. Cheonnam, Sinan-gun, Bigumdo, Gurimri; 19 Oct. 1986, 1 juv. S.J. Yoo coll.

Prov. Cheonnam, Sinan-gun, Huksando, Jinri; 22 July 1986, $1 \%$ and 1 juv. J.M. Lim coll.

Prov. Cheonnam, Yeocheon-gun, Geomundo, Seodori; 23 July 1986, 4 juvs. D.R. Lee coll.

Description. - Largest female (with poorly setose oostegites) $15.5 \mathrm{~mm}$. Female habitus as in fig. 10a.

Female (holotype): Rostrum (fig. 10b) short. Eyes medium.

Antenna 1 (fig. 10c), peduncle segment 2 about 0.9 times as long as segment 1 . Accessory flagellum 9-segmented; primary flagellum 10-segmented, bearing single aesthetasc on segments 4 to 9 .

Antenna 2 (fig. 10d), peduncle segment 3 with 8 facial setae, segments 4 and 5 with 2 groups of facial spines, respectively, flagellum 13-segmented.

Upper lip (fig. 10e), epistome small, lower margin slightly produced medially.
Mandibles (figs. 10f, g), right 10 rakers, left 12; molar with 7 primary spines plus 1 disjunct barbed spine. Palp segment 3 with 2 groups of marginal setae laterally.

Lower lip (fig. 10h) with lateral cone on each outer lobe.

Maxilla 1 (fig. 10i), number of median denticles on the apical spines $=5,1,1,1,1,1,1,1,1,0$, and 1 from inner to outer side, respectively.

Maxilla 2 (fig. 10j), inner lobe slightly narrower than outer.

Maxilliped (fig. 10k), inner margin of outer lobe with 8 long barbed spines and 3 simple proximal setae, palp segment 1 with 5 apicolateral setae, segment 4 about as long as segment 3 , unguis minute.

Coxal plates $1-4$ (figs. $11 \mathrm{a}-\mathrm{d}$ ), posteroventral corner of plates $1-3$ with small cusp, plate 4 rectangular.

Gnathopods 1 and 2 (figs. 11a, b): palm oblique, palmar humps large, width ratios of carpus: propodus of gnathopods 1 and $2=28: 31$ and 27:32, length ratios $=67: 61$ and 63:60.

Pereiopods 3 and 4 (figs. 11c, d) similar to each other but segments 4 and 5 stouter in pereiopod 4; segment 6 with 13 outer and 11 inner spines posteriorly, claw about 0.26 times as long as segment 6 .

Pereiopod 5 (fig. 11e), segment 4 with 5 facial, 4 anterior and 4 posterior marginal spine groups, proximoposterior margin bevelled; segment 5 with 2 facial, 4 anterior and 5 posterior spine groups; segment 6 with 4 anterior and 4 posterior spine groups; width ratios of segments $2,4,5,6=56: 57$ : $45: 20$, length ratios $=97: 40: 45: 37$, claw short.

Pereiopod 6 (fig. 11f), segment 4 with 1 group of 2 proximofacial setae, 2 facial, 4 anterior and 4 posterior marginal spine groups; segment 5 with 1 facial, 2 anterior and 4 posterior spine groups; segment 6 with 6 anterior and 5 posterior spine groups; width ratios of segments $2,4,5,6=81: 51: 45: 18$, length ratios $=98: 60: 60: 70$, claw short.

Pereiopod 7 (fig. 11g), segment 2 distally widened; segments 5-6, medial apex combed, anterior margin with 3-5 groups of small spines; length ratios of segments $2,4,5,6=93: 27: 31: 35$. Claw about 0.57 times as long as segment 6 . 


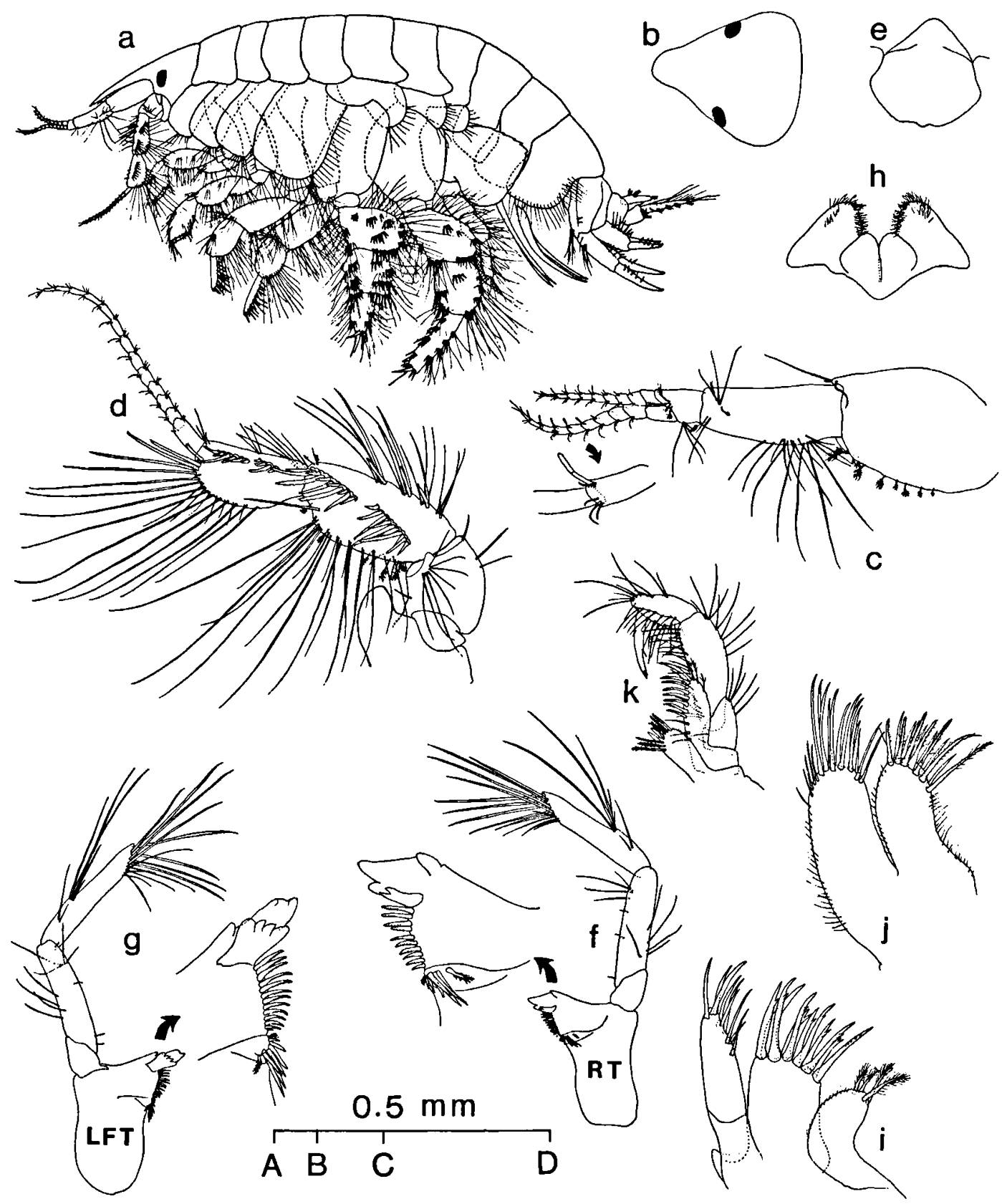

Fig. 10. Grandifoxus malipoensis n. sp. ( $\$$ holotype $11.5 \mathrm{~mm}$ from Malipo). a, entire animal, from the left; b, head, dorsal view (scale $A B)$; c, antenna 1 (AC); d, antenna 2 (AC); e, upper lip (AC); f, right mandible (AC); g, left mandible (AC); $h$, lower lip (AC); i, maxilla 1 (AD); j, maxilla 2 (AD); k, maxilliped (AC). Each scale unit (AB, AC, AD) represents $0.5 \mathrm{~mm}$.

Pleopods 1 (fig. $11 \mathrm{~h}$ ) and 2 similar, rami about 2.4 times as long as peduncle, the inner one 16-, the outer 22-segmented. Peduncle of pleopod 3 (fig. 11i) smaller but rami longer than those of pleopods
1-2, rami about 3 times as long as peduncle.

Coxal gills (figs. $12 a-f$ ): that on pereiopod 7 smallest, unilobed.

Oostegites on gnathopod 2 to pereiopod 5 (figs. 

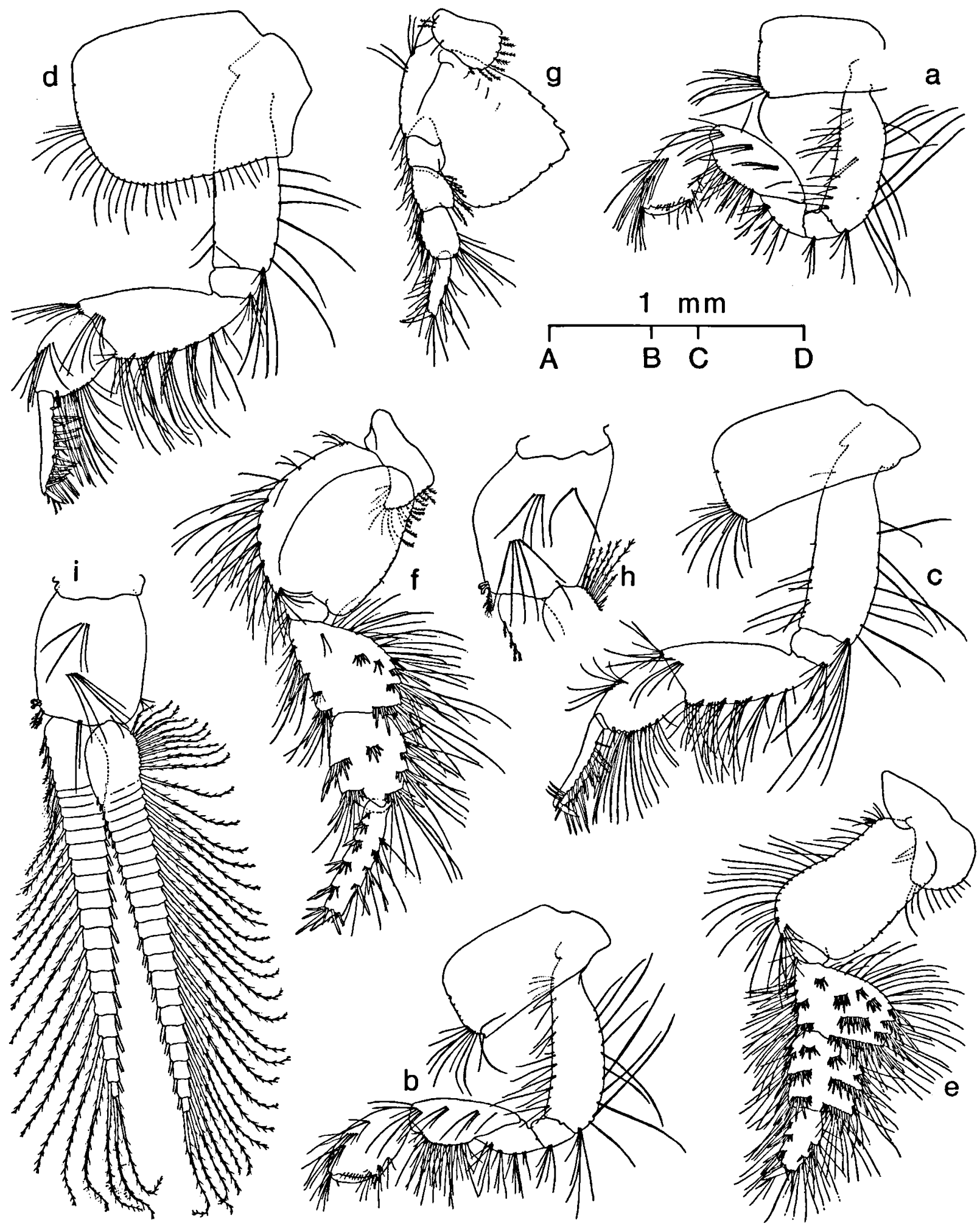

Fig. 11. Grandifoxus malipoensis n. sp. ( $\odot$ holotype $11.5 \mathrm{~mm}$ from Malipo). a, gnathopod 1 (scale AC); b, gnathopod 2 (AC); c, pereiopod 3 (AC); d, pereiopod 4 (AC); e, pereiopod 5 (AB); f, pereiopod 6 (AB); g, pereiopod 7 (AB); h, peduncle of pleopod 1 (AD); i, pleopod 3 (AD). Each scale unit (AB, AC, AD) represents $1 \mathrm{~mm}$. 

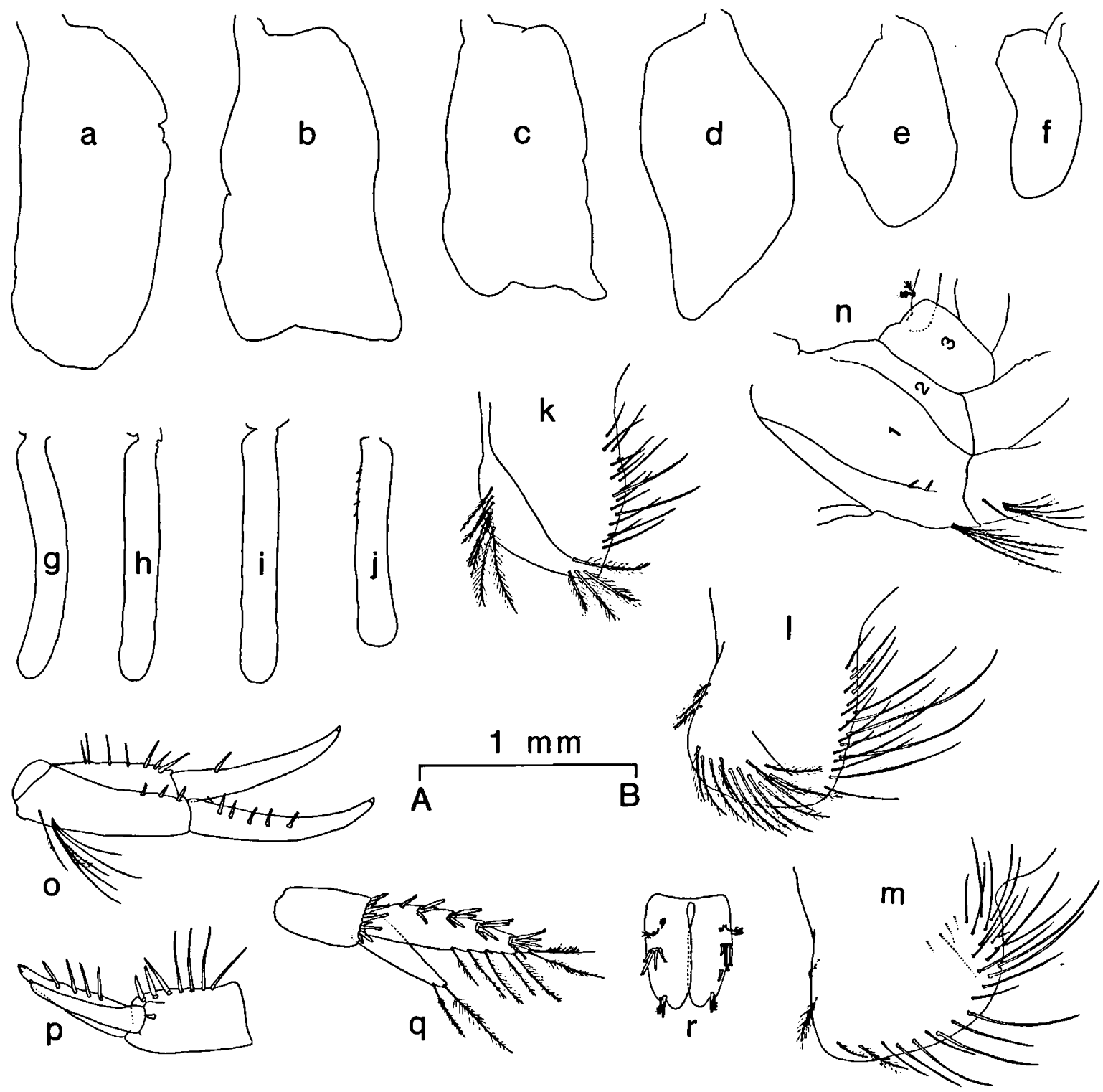

Fig. 12. Grandifoxus malipoensis n. sp. ( $(9$ holotype $11.5 \mathrm{~mm}$ from Malipo). a-f, coxal gills on gnathopod $2-$ pereiopod $7 ; \mathrm{g}-\mathrm{j}$, oostegites on gnathopod 2 - pereiopod $5 ; k-m$, epimeral plates $1-3 ; n$, urosomites; o-q, uropods $1-3 ; r$, telson. Scales: all AB (=1 $\mathrm{mm})$.

$12 \mathrm{~g}-\mathrm{j})$, linear, setation not fully developed in the holotype, that on pereiopod 5 with 5 anterior marginal setules.

Epimeral plates 1-3 (figs. 12k-m): posterior margin of plate 1 with 16 setae, posteroventral corner with 4 plumose setae, anterodistal margin with 8 plumose setae; posterior margin of plate 2 with 18 setae, subventral margin densely setose (13 plumose setae); posterior and ventral margins of plate 3 continuously setose.

Pleosomites 1-3 with several dorsal spines. Urosomite 1 (fig. 12n) not spinose on dorsal margin, with 2-3 lateral spines on facial ridge and ventrodistal setal group, articulation between urosomites 1 and 2 incomplete dorsally.

Uropod 1 (fig. 12o), peduncle with 2 groups of 1 
and 5 basofacial setae, outer margin with 3 short spines, inner with 4 slender spines and 3 blunt spines; outer ramus slightly longer than peduncle, with 5 dorsal spines, inner with a dorsal spine and proximoventral seta.

Uropod 2 (fig. 12p), peduncle as long as rami, outer margin with 4 slender and 3 normal spines, inner with single short spine; outer ramus with 4 dorsal spines, inner without spines.

Uropod 3 (fig. 12q), inner ramus about 0.71 times as long as segment 1 of outer ramus; outer ramus, spine groups of segment 1 with 1-3-4-4-5 spines from proximal to distal, respectively.

Telson (fig. 12r) longer than wide, apices with a spine and setule, dorsolateral margin of left lobe with a pair of setules and group of 4 spines, right lobe with 2 setules and 2 groups of 1 and 4 spines.

Male: Unknown.

Remarks. - From the American species G. grandis the new species is distinguished as follows: dorsal spines on the inner ramus of uropod 2 lacking, coxal plates 1-3 with small cusps, peduncle of uropod 2 with long slender spines, segment 2 of pereiopod 7 widened distally, and epimeral plate 3 rounded posterodistally.

G. malipoensis is distinguished from the northwestern Pacific species $G$. lindbergi by: the presence of facial spines on urosomite 1 and dorsal spines on peduncle segment 4 of antenna 2 , high number of spine groups on the posterior margin of segment 6 of pereiopod 5 , and the densely setose posterior margin of epimeral plate 1 .

G. malipoensis rather closely resembles the other Korean species, G. cuspis, in many respects, but differs from the latter in the following points: the small cusp of coxal plates $1-3$, the smaller teeth on the posterior margin of segment 2 of pereiopod 7 , the lower number of facial spine groups on segment 4 of pereiopods 5 and 6 , and the short spines on the outer margin of peduncle of uropod 1.

In general, smaller specimens of $G$. malipoensis $(5.3-5.6 \mathrm{~mm})$ agree well with the adults but they differ in the following features: a single facial spine group on peduncle segment 5 of antenna 2, a single setal group on mandibular palp segment 3 , the ab- sence of spines on the inner ramus of uropod 1 , and the short inner ramus of uropod 3 (about half the length of segment 1 of outer ramus).

The number of facial spine groups on segments 4-5 of pereiopods 5-6 is consistent even in smaller animals of the species. Accordingly, this is considered to be a good character for identifying the Korean species of Grandifoxus (especially $G$. malipoensis and G. cuspis). Coyle (1982) recommends, however, careful application of such characters in Alaskan waters because of the tendency to vary with respect to age, size and maturity.

A large female $(15.5 \mathrm{~mm}$, with weakly setose oostegites) from Hakampo hardly differs from the holotype except for having paired spine groups on the inner margin of peduncle of uropod 1. Another female $(12.0 \mathrm{~mm})$ from Huksando has richly spinose rami of uropods 1-2 (uropod 1, outer ramus with 8, inner with 3 dorsal spines; uropod 2, outer ramus with 7 , inner without dorsal spines).

Etymology. - The specific name alludes to the type-locality, Malipo, which is an attractive summer resort in the Seosan Sea Coast National Park.

Distribution and ecology. - G. malipoensis was collected primarily on the west coast of Korea from the intertidal to the infralittoral (up to $100 \mathrm{~cm}$ deep) on fine sandy bottoms.

Grandifoxus cuspis n. sp. (figs. 13-15)

Material examined. - Prov. Chungnam, Seosan-gun, Malipo; 21 Oct. 1986, $1 \&$ holotype (ZMA Amph. 108.570) and 1 \% paratype (IMS). Y.W. Jo coll.

Prov. Chungnam, Seosan-gun, Hakampo; 28 June 1987, 1 \&. H.J. Ko coll.

Description. - Females (with weakly setose oostegites) up to $12.4 \mathrm{~mm}$.

Female (holotype): Rostrum (figs. 13a, b) neither very short nor narrow, eyes small.

Antenna 1 (fig. 13c), peduncle segment 2 about 0.66 times as long as segment 1 . Accessory flagellum 8-segmented, primary flagellum 9-segmented, bearing single aesthetasc on segments 4 to 7 .

Antenna 2 (fig. 13d), peduncle segment 3 with 7 

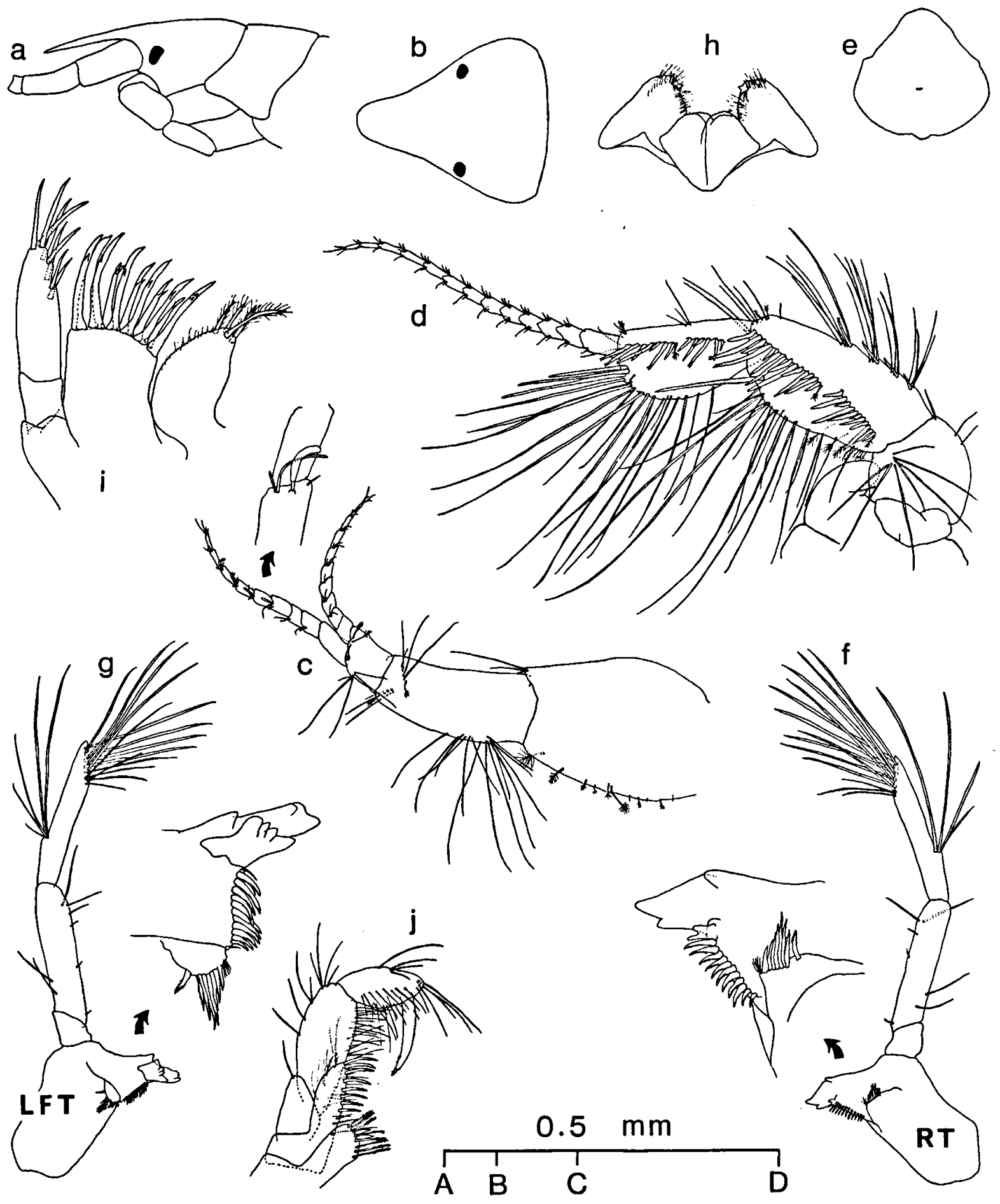

Fig. 13. Grandifoxus cuspis n. sp. ( 9 holotype $11.0 \mathrm{~mm}$ from Malipo). a, head (scale AB); b, head, dorsal view (AB); c, antenna 1 (AC); d, antenna 2 (AC); e, upper lip (AC); f, right mandible (AC); g, left mandible (AC); h, lower lip (AC); i, maxilla 1 (AD); j, maxilliped (AC). Each scale unit (AB, AC, AD) represents $0.5 \mathrm{~mm}$. 

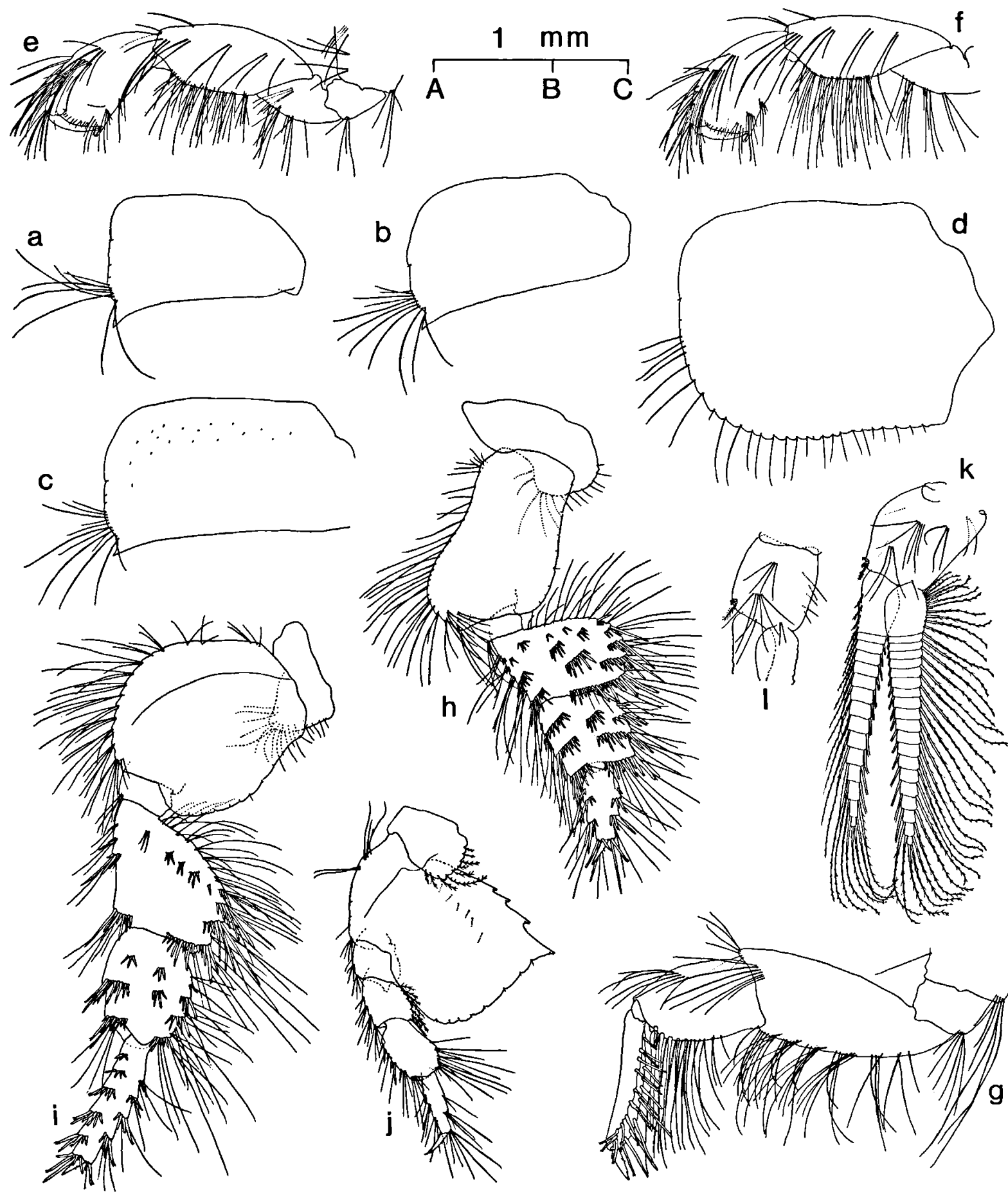

Fig. 14. Grandifoxus cuspis n. sp. ( 9 holotype $11.0 \mathrm{~mm}$ from Malipo). a-d, coxal plates 1-4 (scale AC); e, distal part of gnathopod 1 (AC); f, distal part of gnathopod 2 (AC); g, distal part of pereiopod 3 (AC); h, pereiopod 5 (AB); i, pereiopod 6 (AB); j, pereiopod 7 (AB); k, pleopod 1 (AC); 1, peduncle of pleopod 3 (AC). Each scale unit $(A B, A C)$ represents $1 \mathrm{~mm}$. 

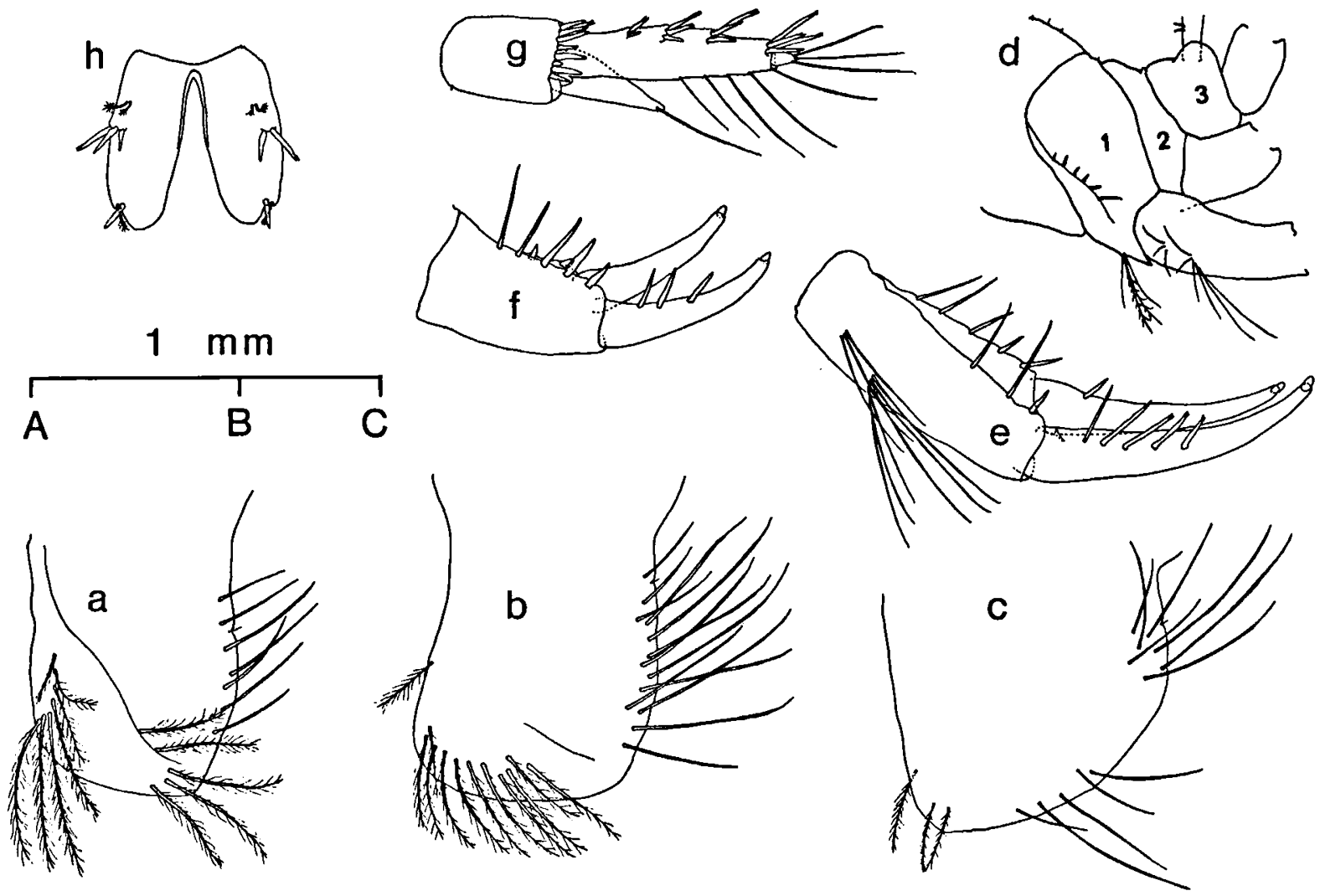

Fig. 15. Grandifoxus cuspis n. sp. (\% holotype $11.0 \mathrm{~mm}$ from Malipo). a, epimeral plate 1 (scale AC); b, epimeral plate 2 (AC); c, epimeral plate $3(\mathrm{AC})$; d, urosomites $(\mathrm{AB})$; e, uropod 1 (AC); f, uropod 2 (AC); g, uropod 3 (AC); h, telson (AC). Each scale unit (AB, AC) represents $1 \mathrm{~mm}$.

facial setae, segments 4 and 5 with 2 groups of facial spines, respectively; flagellum 13-segmented.

Upper and lower lips (figs. 13e,h) similar to the previous species.

Mandibles (figs. 13f,g), right lacinia mobilis short; right 11 rakers, left 11 plus a few simple blades; molar with 7 spines plus 1 displaced spine; palp segment 3 with a group of outer marginal setae.

Maxilla 1 (fig. 13i), apical spines of outer lobe with $2,1,1,1,1,1,1,1,1,0$, and 1 median denticles from inner to outer side, respectively; maxilla 2 similar to the previous species.

Maxilliped (fig. 13j), palp segment 1 with single apical seta, segment 4 as long as segment 3 , unguis minute.

Coxal plates 1-4 (figs. $14 \mathrm{a}-\mathrm{d}$ ), posteroventral corner of plates $1-3$ with strong cusp, plate 4 rectangular.
Gnathopods 1 and 2 (figs. 14e, f): palm weakly oblique, palmar humps large, width ratios of carpus: propodus of gnathopods 1 and $2=51: 52$ and 48:52, length ratios $=122: 103$ and $127: 102$.

Pereiopods 3 (fig. 14g) and 4 similar, segment 6 with 2 rows of 11 and $12-14$ posterior spines, claw about 0.26 times as long as segment 6 .

Pereiopod 5 (fig. 14h), proximoposterior margin of segment 4 not bevelled, parallel to distal margin, with 7 facial, 4 anterior and 5 posterior marginal spine groups; segment 5 with 1 facial, 4 anterior and 4 posterior spine groups; segment 6 with 4 anterior and 4 posterior spine groups; width ratios of segments $2,4,5,6=57: 56: 40: 18$, length ratios $=92: 39$ : 42:38, claw short.

Pereiopod 6 (fig. 14i), segment 4 with 1 group of 3 proximofacial setae, 4 facial, 4 anterior and 4 posterior marginal spine groups; segment 5 with 3 facial, 2 anterior and 4 posterior spine groups; seg- 
ment 6 with 6 anterior and 5 posterior spine groups; width ratios of segments $2,4,5,6=85: 55: 44: 18$, length ratios $=94: 62: 57: 67$, claw short.

Pereiopod 7 (fig. 14j), segment 2 distally widened, posterodistal corner remarkably pointed; medial apex of segments 5-6 combed, anterior margin with 3-5 groups of small spines; length ratios of segments $2,4,5,6=93: 26: 34: 32$, claw about 0.48 times as long as segment 6 .

Pleopods 1 (fig. 14k) and 2 similar, inner ramus 15-, outer 20-segmented, outer ramus about 2.6 times as long as peduncle; peduncle of pleopod 3 (fig. 14l) shorter than those of pleopods 1-2, outer ramus about 3.1 times as long as peduncle.

Oostegites, setation not fully developed in this material, that on pereiopod 5 with 3 anterior marginal setules.

Epimeral plates 1-3 (figs. 15a-c): posterior margin of plate 1 with 7 setae, posteroventral corner with 5 plumose setae, anterodistal corner with 7 plumose setae; posterior margin of plate 2 with 13 setae, subventral margin with 11 plumose setae; plate 3 with 7 posteromarginal setae narrowly spread and 5 ventral setae.

Pleosomites 1-3 with a few dorsal spinules. Urosomite 1 (fig. 15d) not spinose on dorsal margin, with 6 lateral spines along the facial ridge (posteriormost longest) and group of ventral setae, articulation line between urosomites 1 and 2 almost complete dorsally.

Uropod 1 (fig. 15e), peduncle with 2 groups of 3 and 6 basofacial setae, outer margin with 2 slender and 1 short spines, inner with 2 thin and 3 blunt spines; outer ramus longer than peduncle, with 5 tall dorsal spines, inner with 1 dorsal spine and proximoventral seta.

Uropod 2 (fig. 15f), peduncle as long as rami, outer margin with 2 slender and 3 blunt spines, inner with 2 short, stout spines; outer ramus with 3 dorsal spines, inner naked.

Uropod 3 (fig. $15 \mathrm{~g}$ ), inner ramus about 0.54 times as long as segment 1 of outer ramus; segment 1 of outer ramus with 2-3-3-4 lateral spines from proximal to distal.

Telson (fig. 15h), apices with 1 spine and 1 setule, dorsolateral margin with 2 setules and 2-3 spines on either side.
Male: Unknown.

Remarks. - G. cuspis is similar to G. grandis by the large tooth on coxal plate 1-3, but differs from the latter by the absence of dorsal spines on the inner ramus of uropod 2, the short inner ramus of uropod 3 , and the strongly pointed posterior margin of segment 2 of pereiopod 7.

A female $(12.4 \mathrm{~mm})$ from Hakampo slightly differs from the holotype in pereiopod 5 (segments 4 and 5 with 8 and 2 facial spine groups, respectively) and uropod 2 (peduncle with a single dorsal spine on the inner margin).

Etymology. - The name cuspis is derived from the Latin, meaning point, which refers to the sharp cusps of the coxal plates and segment 2 of the 7 th pereiopod.

Distribution and ecology. - The new species was found on fine sandy bottoms at Malipo and Hakampo, and co-occured with $G$. malipoensis at both localities.

Grandifoxus bangpoensis n. sp. (figs. 16-18)

Material examined. - Prov. Chungnam, Seosan-gun, Bangpo; 20 Oct. 1986, 1 \& holotype (ZMA Amph. 108.571), 11 paratypes (ZMA Amph. 108.572) and 11 paratypes (IMS). Y.W. Jo \& H.J. Ko coll.

Prov. Kyeongki, Ongjin-gun, Baekryeongdo, Yongkipo; 4 Nov, 1986, $1 \odot$ and 7 juvs. B.S. Yeo \& M.S. Jo coll.

Prov. Chungnam, Seosan-gun, Malipo; 21 Oct. 1986, 1 \% and 6 juvs. Y.W. Jo coll.

Description. - Females (without setae on oostegites) up to $6.6 \mathrm{~mm}$.

Female (holotype): Rostrum (figs. 16a, b) short, narrow. Eyes medium.

Antenna 1 (fig. 16c), peduncle segment 2 about 0.6 times as long as segment 1 . Both accessory and primary flagellum of 8 segments, primary flagellum with single aesthetasc on segments 4 to 7 .

Antenna 2 (fig. 16d), peduncle segment 3 with 4 facial setae, segments 4 and 5 with 2 and 1 groups of facial spines, respectively; flagellum 10-segmented. 

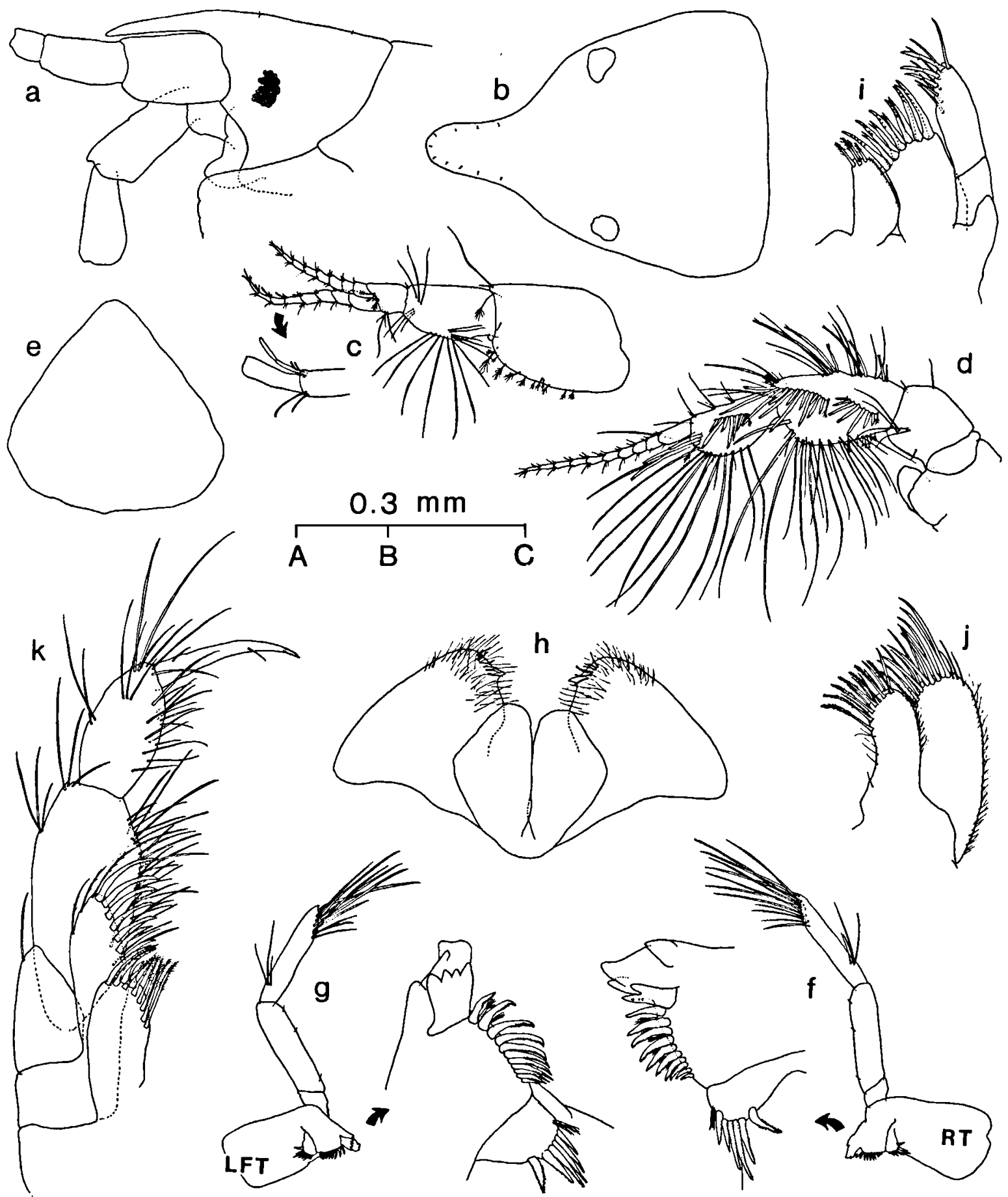

Fig. 16. Grandifoxus bangpoensis n. sp. (a, ९ paratype $6.0 \mathrm{~mm}$; b-k, ᄋ holotype $6.6 \mathrm{~mm}$, from Bangpo). a, head (scale AB); b, head, dorsal view (AB); c, antenna 1 (AB); d, antenna 2 (AB); e, upper lip (AC); f, right mandible (AB); g, left mandible (AB); h, lower lip $(A C)$; i, maxilla 1 ( $A C)$; j, maxilla 2 ( $A C)$; k, maxilliped (AC). Each scale unit (AB, $A C$ ) represents $0.3 \mathrm{~mm}$. 


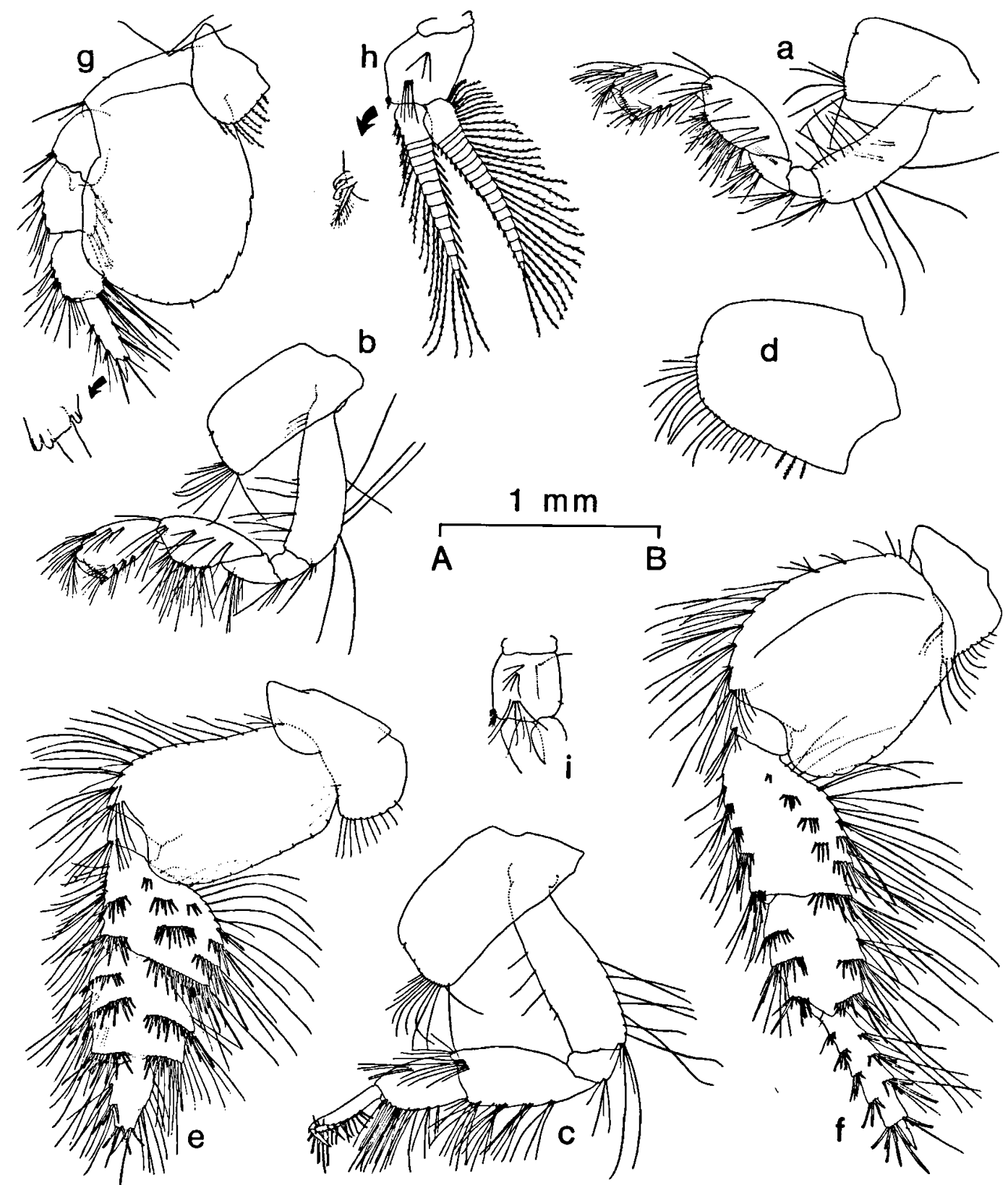

Fig. 17. Grandifoxus bangpoensis $\mathrm{n}$. sp. ( $\odot$ holotype $6.6 \mathrm{~mm}$ from Bangpo). a, gnathopod 1; b, gnathopod 2; c, pereiopod 3; d, coxal plate 4; e, pereiopod 5; f, pereiopod 6; g, pereiopod 7; h, pleopod 1; i, peduncle of pleopod 3. Scales: all AB (=1 mm).

Upper and lower lips (figs. 16e, h): lateral margins of upper lip straight, triangular.

Mandibles (figs. 16f, g), right 10 rakers, left 11; molar with 5 primary spines plus 1 disjunctive spine; outer margin of palp segment 2 naked, inner margin with 3 setules, segment 3 with group of outer marginal setae.
Maxilla 1 (fig. 16i), apical spines of outer lobe with many denticles (bearing $5,1,4,1,4,1,4,1,3,0$, and 2 median denticles from inner to outer side, respectively).

Maxilla 2 (fig. 16j), inner lobe much smaller than outer.

Maxilliped (fig. 16k), palp segment 1 with single 

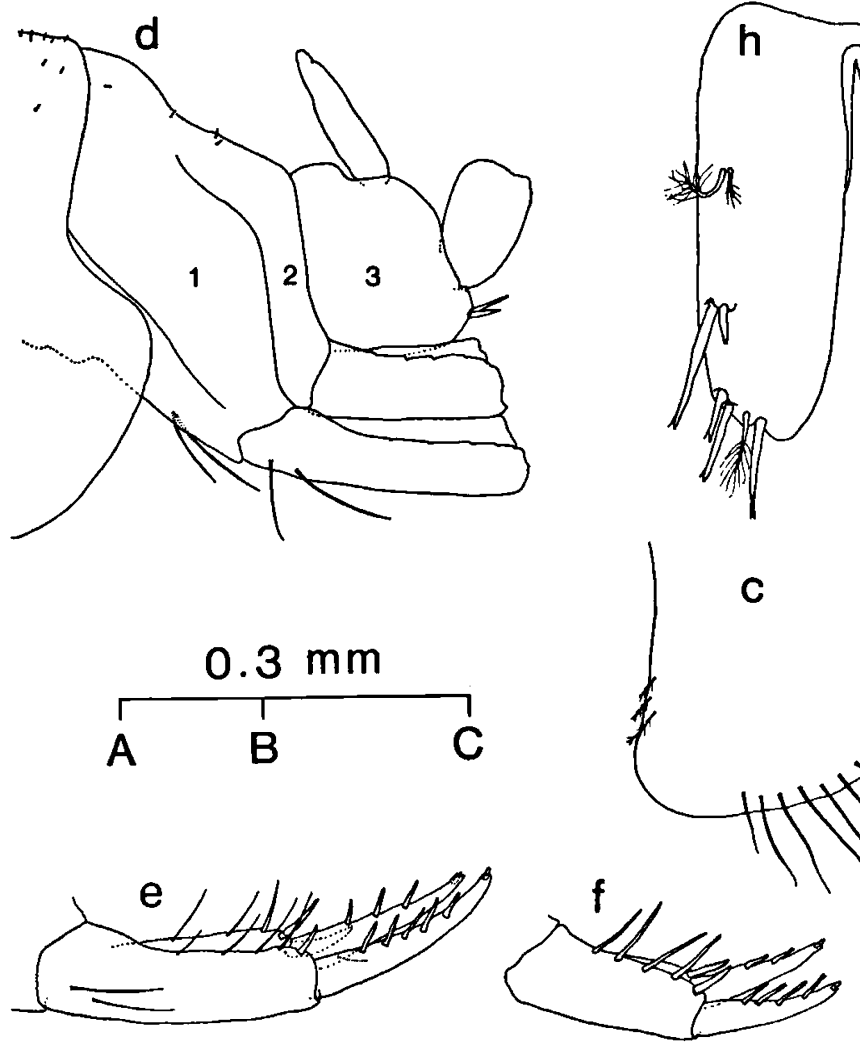
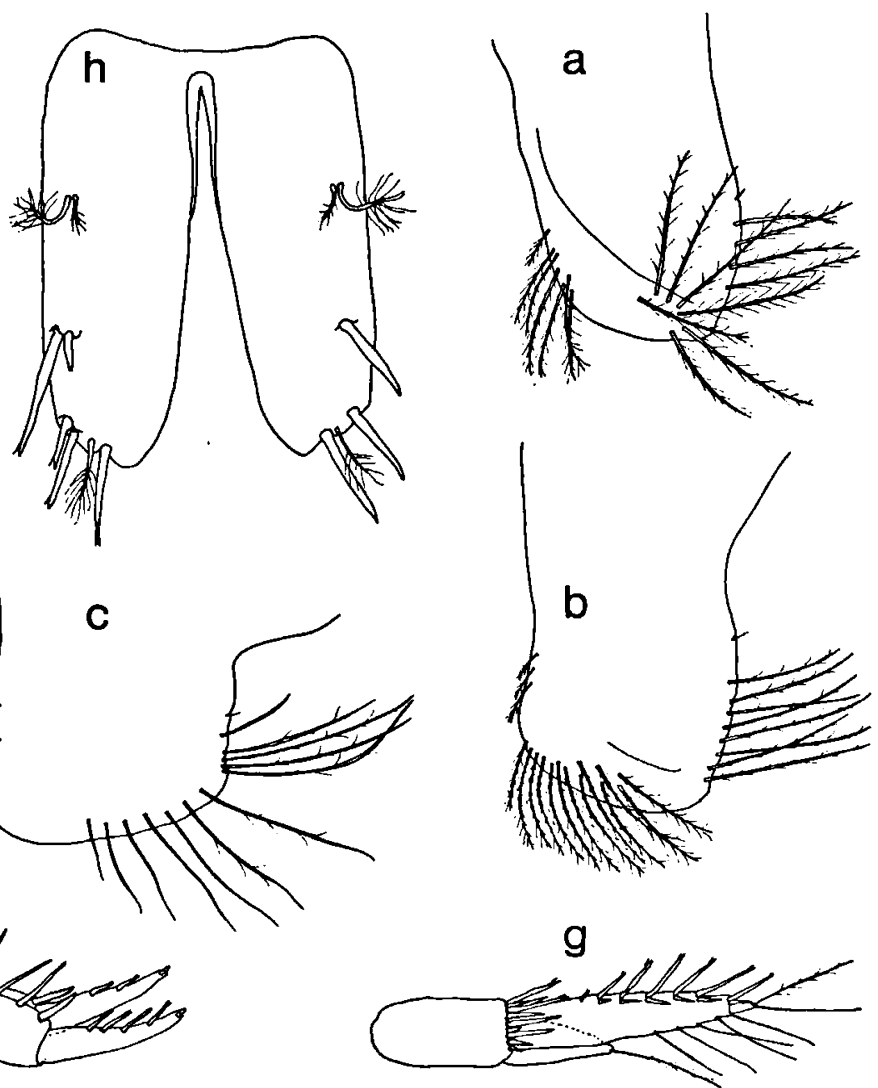

Fig. 18. Grandifoxus bangpoensis n. sp. ( 9 holotype $6.6 \mathrm{~mm}$ from Bangpo). a, epimeral plate 1 (scale AB); b, epimeral plate 2 (AB); c, epimeral plate 3 (AB); d, urosomites (AB); e, uropod 1 (AB); f, uropod 2 (AB); g, uropod 3 (AB); h, telson (AC). Each scale unit $(A B, A C)$ represents $0.3 \mathrm{~mm}$.

apicolateral seta, segment 4 slightly longer than segment 3, unguis hardly visible.

Coxal plates 1-4 (figs. 17a-d): posteroventral corner of plates $1-3$ rounded, lacking cusp, plate 4 narrowing distally.

Gnathopods 1 and 2 (figs. 17a, b): palm weakly oblique, palmar humps distinct, width ratios of carpus: propodus of gnathopods 1 and $2=35: 33$ and $34: 32$, length ratios $=77: 65$ and $74: 61$.

Pereiopods 3 (fig. 17c) and 4, segment 6 with 10 outer and 10 inner spines, claw about 0.3 times as long as segment 6.

Pereiopod 5 (fig. 17e), segment 4 with 4 facial, 4 anterior and 4 posterior marginal spine groups; segment 5 with 0-3-2 spine groups; segment 6 with 3 anterior and 1 posterior spine groups; width ratios of segments $2,4,5,6=94: 86: 73: 29$, length ratios $=135: 70: 79: 51$, claw about 0.42 times as long as segment 6.

Pereiopod 6 (fig. 17f), segment 4 longish, not strongly expanded posteriorly, with 4 facial, 6 anterior and 4 posterior spine groups; segment 5 with 3 anterior and 3 posterior spine groups; segment 6 with 5 anterior and 4 posterior spine groups; width ratios of segments $2,4,5,6=130: 75: 62: 22$, length ratios $=150: 110: 88: 89$, claw about 0.27 times as long as segment 6 .

Pereiopod 7 (fig. 17g), segment 2 distally narrowing, rounded; segment 4 as long as segment 5; segments 5-6, medial apex combed, anterior margins with small spines; length ratios of segments $2,4,5,6=160: 48: 48: 50$, claw about 0.32 times as long as segment 6 .

Pleopods 1 (fig. 17h) and 2, inner ramus 14- (or 12-), outer 16-segmented, outer ramus about 2.5 times as long as peduncle; peduncle of pleopod 3 
(fig. 17i) shorter but rami longer than those of pleopods 1 and 2, outer ramus about 3 times as long as peduncle.

Oostegites poorly developed in this specimen, lacking setae.

Epimeral plates 1-3 (figs. 18a-c): posterior margin of plate 1 with 4 plumose setae spread over narrow stretch, 7 plumose setae on posteroventral corner, and 7 anterior marginal setae; posterior margin of plate 2 with 8 setae, ventral margin with 13 setae; plate 3 with 5 posteromarginal and 7 ventral setae.

Pleosomites 1-3 with several spinules along the dorsal margin. Urosomite 1 (fig. 18d), lateral spines on the facial ridge lacking, with 2 ventral setae, dorsal margin of urosomites 1 and 2 with a few spinules, articulation between urosomites 1 and 2 incomplete dorsally; posteroventral corner of urosomite 3 with 2 medium long spines.

Uropod 1 (fig. 18e), peduncle with 2 basofacial setae, outer margin with 4 slender and 1 blunt spines, inner with 3 slender and 1 blunt spines plus enlarged apicomedial spine; rami shorter than peduncle, outer ramus with 5 dorsal spines, inner with 3 dorsal spines and a long proximoventral seta.

Uropod 2 (fig. 18f), peduncle longer than rami, outer margin with 4 long and 1 blunt spines, inner with single spine; outer ramus with 4 , inner with 2 dorsal spines.

Uropod 3 (fig. 18g), inner ramus about 0.5 times as long as segment 1 of outer ramus; segment 1 of outer ramus with 7 groups of lateral spines, spine formula $=1-2-2-2-2-2-2$ from proximal to distal.

Telson (fig. 18h), apices with $2-3$ spines plus setule, dorsolateral margin with 1-2 spine(s) and 2 setules on each lobe.

Male: Unknown.

Remarks. - $G$. bangpoensis is smaller than and less similar to the previous two Korean species of the genus. The present species differs from them by: the presence of spines on the inner ramus of uropod 2 and urosomite 3 , the large displaced apicomedial spine on the peduncle of uropod 1 , a single spine group only on the posterior margin of segment 6 of pereiopod 5 , the distally rounded segment 2 of pereiopod 7, and the absence of facial spines on urosomite 1 .

G. bangpoensis closely resembles the Bering Sea species $G$. aciculata. However, G. bangpoensis differs from the latter by having dorsal spines on the peduncle segment 4 of antenna 2 , a single spine group only on the posterior margin of segment 6 of pereiopod 5 , and 6 spines on the mandibular molar (8 spines in G. aciculata).

In this species, the uropod 3 is of the variiramus type (Stock, 1974). Within the same population the length of the inner ramus varies from $1 / 2$ to $3 / 4$ of the length of segment 1 of the outer ramus regardless of their size. Some specimens from the typelocality and Malipo have a considerably large number of segments (16-24) in the flagellum of antenna 2. The number of spines on the posteroventral corner of urosomite 3 is variable from 2 to 4 .

Etymology. - The new species is named after the type-locality Bangpo.

Distribution and ecology. - G. bangpoensis was collected in the middle part of the west coast of Korea on beaches with fine sandy sediments. It is expected that its distribution might extend northwards to China. At Malipo and Baekryeongdo the present species co-occured with $G$. malipoensis.

\section{Acknowledgements}

The author is indebted to the following persons for their assistance with collecting the material: Sister Ignatius (Bok Soon) Yeo and Ms. Myeong Sook Jo of Baekryeong Catholic Church, Mr. Ho Jong Ko of Koryeo Farm, Mr. Seok Ju Yoo of Bigum Primary School, Mr. Kwon Cheol Yoo of Docho Primary School, Mr. Jeong Man Lim of Huksan Primary School, Mr. Dong Ryeol Lee of Geomun Seodo Primary School, and the students of the Department of Marine Biology, National Fisheries University of Pusan (NFUP), who joined the Field Biology Course of 1986 to Cheju Island led by Prof. Young Joo Kang. Special thanks must be given to Prof. Dr. Jan H. Stock of the Institute of Taxonomic Zoology (ITZ), University of Amsterdam for his helpful comments and for review of the manuscript. Ir. Jos Notenboom of the ITZ is thanked for critical reading of the manuscript. The author is grateful to Drs. Florence F.J.M. Pieters of the Artis Library and Mr. Jelle Paul of the Library of ITZ for their kind assistance in procuring old literature.

This study was supported by the Netherlands Universities 
Foundation for International Cooperation (NUFFIC/UNESCO), The Hague.

\section{References}

Barnard, J.L., 1957. A new genus of phoxocephalid Amphipoda (Crustacea) from Africa, India, and California. Ann. Mag. nat. Hist., (12) 10: 432-438.

Barnard, J.L., 1979. Revision of American species of the marine amphipod genus Paraphoxus (Gammaridea: Phoxocephalidae). Proc. biol. Soc. Wash., 92(2): 368-379.

Barnard, J.L., 1980. The genus Grandifoxus (Crustacea: Amphipoda: Phoxocephalidae) from the northeastern Pacific Ocean. Proc. biol. Soc. Wash., 93(2): 490-514.

Barnard, J.L. \& C.M. Barnard, 1982. Revision of Foxiphalus and Eobrolgus (Crustacea: Amphipoda: Phoxocephalidae) from American oceans. Smithson. Contr. Zool., 372: 1-35.

Barnard, J.L. \& M.M. Drummond, 1976. Clarification of five genera of Phoxocephalidae (Marine Amphipoda). Proc. biol. Soc. Wash., 88(49): 515-548.

Barnard, J.L. \& M.M. Drummond, 1978. Gammaridean Amphipoda of Australia, part III: The Phoxocephalidae. Smithson. Contr. Zool., 245: 1-551.

Coyle, K.O., 1982. The amphipod genus Grandifoxus Barnard (Gammaridea, Phoxocephalidae) in Alaska. J. crust. Biol., 2(3): $430-450$.

Giles, G.M., 1890. Descriptions of seven additional new Indian amphipods. Number 15. In: Natural History Notes from H.M. Indian Marine Survey Steamer 'Investigator,' Commander Alfred Carpenter, R.N., D.S.O., commanding. J. asiatic Soc. Bengal, 59: 63-74.

Griffiths, C.L., 1976. Some new and notable Amphipoda from southern Africa. Ann. S. afr. Mus., 72(2): 11-35.

Gurjanova, E.F., 1936. Neue Beiträge zur Fauna der CrustaceaMalacostraca des arktischen Gebietes. Zool. Anz., 113: 245-255.

Gurjanova, E.F., 1938. Amphipoda, Gammaroidea of Siaukhu
Bay and Sudzukhe Bay (Japan Sea). Report of the Japan Sea Hydrobiological Expedition of the Zoological Institute of the Academy of Science, USSR, in 1934, 1: 241-404 [in Russian with English summary].

Gurjanova, E.F., 1951. Gammarids of the seas of the USSR and adjacent waters (Amphipoda-Gammaridea). Keys to the Fauna of the USSR, Zool. Inst. Acad. Sci. USSR, 41: 1-1029 [in Russian].

Gurjanova, E.F., 1953. Novye dopolnenija k dal'nevostochnoi faune morskikh bokoplavov. Trudy zool. Inst. Akad. Nauk SSSR, 13: 216-241.

Gurjanova, E.F., 1977. Some new data in taxonomy of family Phoxocephalidae sensu lato (Amphipoda, Gammaridea). Report I. Explorations of the Fauna of the Seas (Acad. Sci. USSR), 21(29): 67-87 [in Russian with English summary].

Gurjanova, E.F., 1980a. Some new data in taxonomy of family Phoxocephalidae sensu lato (Amphipoda, Gammaridea). Report II. Explorations of the Fauna of the Seas (Acad. Sci. USSR), 25(33): 89-97 [in Russian with English summary].

Gurjanova, E.F., 1980b. Some new data in taxonomy of family Phoxocephalidae sensu lato (Amphipoda, Gammaridea). Report III. Explorations of the Fauna of the Seas (Acad. Sci. USSR), 25(33): 98-100 [in Russian with English summary].

Nayar, K.N., 1959. The Amphipoda of the Madras coast. Bull. Madras Govern. Mus., (new Ser.) (nat. Hist.) 6(3): 1-59.

Pillai, N.K., 1957. Pelagic Crustacea of Travancore. IIl. Amphipoda. Bull. centr. Res. Inst., Univ. Travancore, (C) (nat. Sci.) 5(1): 29-68.

Stimpson, W., 1856. On some Californian Crustacea. Proc. California Acad. Sci., 1: 95-99.

Stock, J.H., 1974. The systematics of certain Ponto-Caspian Gammaridae (Crustacea, Amphipoda). Mitt. hamb. zool. Mus. Inst., 70: 75-95.

Thorsteinson, E.D., 1941. New or noteworthy amphipods from the North Pacific coast. Univ. Wash. Publ. Oceanogr., 4:50-96.

Received: 8 February 1989. 